\title{
Estimation of maize above-ground biomass based on stem- leaf separation strategy integrated with LiDAR and optical remote sensing data
}

\author{
Yaohui Zhu ${ }^{1,2,3}$, Chunjiang Zhao \\ Feng $^{2,3}$, Bo Xu ${ }^{2,3}$, Jintao Wu ${ }^{2,3}$, Lei Lei ${ }^{2,3}$ \\ Hao Yang ${ }^{\text {Corresp., 2, } 3 \text {, Guijun Yang }}{ }^{2,3}$, Liang Han ${ }^{2,4}$, Zhenhai Li ${ }^{2,3}$, Haikuan \\ ${ }^{1}$ School of Information Science and Technology, Beijing Forestry University, Beijing, China \\ 2 Key Laboratory of Quantitative Remote Sensing in Agriculture of Ministry of Agriculture, Beijing Research Center for Information Technology in \\ Agriculture, Beijing, China \\ 3 National Engineering Research Center for Information Technology in Agriculture, Beijing, China \\ 4 College of Architecture and Geomatics Engineering, Shanxi Datong University, Datong, China \\ Corresponding Authors: Chunjiang Zhao, Hao Yang \\ Email address: zhaocj@nercita.org.cn, yangh@nercita.org.cn
}

Above-ground biomass (AGB) is an important indicator for effectively assessing crop growth and yield and, in addition, is an important ecological indicator for assessing the efficiency with which crops use light and store carbon in ecosystems. However, most existing methods using optical remote sensing to estimate AGB cannot observe structures below the maize canopy, which may lead to poor estimation accuracy. This paper proposes to use the stem-leaf separation strategy integrated with unmanned aerial vehicle LiDAR and multispectral image data to estimate the AGB in maize. First, the correlation matrix was used to screen optimal the LiDAR structural parameters (LSPS) and the spectral vegetation indices (SVIs). According to the screened indicators, the SVIs and the LSPs were subjected to multivariable linear regression (MLR) with the above-ground leaf biomass (AGLB) and above-ground stem biomass (AGSB), respectively. At the same time, all SVIS derived from multispectral data and all LSPS derived from LiDAR data were subjected to partial least squares regression (PLSR) with the AGLB and AGSB, respectively. Finally, the AGB was computed by adding the AGLB and the AGSB, and each was estimated by using the MLR and the PLSR methods, respectively. The results indicate a strong correlation between the estimated and field-observed AGB using the MLR method $\left(R^{2}=0.82, R M S E=\right.$ $\left.79.80 \mathrm{~g} / \mathrm{m}^{2}, \mathrm{NRMSE}=11.12 \%\right)$ and the PLSR method $\left(\mathrm{R}^{2}=0.86, \mathrm{RMSE}=72.28 \mathrm{~g} / \mathrm{m}^{2}\right.$, NRMSE $=10.07 \%)$. The results indicate that PLSR more accurately estimates AGB than MLR, with $R^{2}$ increasing by 0.04 , RMSE decreasing by $7.52 \mathrm{~g} / \mathrm{m}^{2}$, and NRMSE decreasing by $1.05 \%$. In addition, the AGB is more accurately estimated by combining LiDAR with

multispectral data than LiDAR and multispectral data alone, with $\mathrm{R}^{2}$ increasing by 0.13 and Peerj reviewing PDF | (2019:04:36493:2:0:NEW 22 Jul 2019) 
0.30 , respectively, RMSE decreasing by 22.89 and $54.92 \mathrm{~g} / \mathrm{m}^{2}$, respectively, and NRMSE decreasing by $4.46 \%$ and $7.65 \%$, respectively. This study improves the prediction accuracy of AGB and provides a new guideline for monitoring based on the fusion of multispectral and LiDAR data. 
1 Estimation of maize above-ground biomass based on stem2 leaf separation strategy integrated with LiDAR and optical

\section{3 remote sensing data}

4 Yaohui Zhu' ${ }^{1,2,3}$, Chunjiang Zhao ${ }^{1,2,3}$, Hao Yang ${ }^{2,3}$, GuijunYang ${ }^{2,3}$, Liang Han ${ }^{2,4}$, Zhenhai Li ${ }^{2,3}$, Haikuan

5 Feng $^{2,3}$, Bo Xu' ${ }^{2,3}$, Jintao $\mathrm{Wu}^{2,3}$, Lei Lei ${ }^{2,3}$

$6 \quad{ }^{1}$ School of Information Science and Technology, Beijing Forestry University, Beijing, China

$7 \quad{ }^{2}$ Key Laboratory of Quantitative Remote Sensing in Agriculture of Ministry of Agriculture, Beijing

8 Research Center for Information Technology in Agriculture, Beijing, China

$9{ }^{3}$ National Engineering Research Center for Information Technology in Agriculture, Beijing, China

$10{ }^{4}$ College of Architecture and Geomatics Engineering, Shanxi Datong University, Datong, China

12 Corresponding Author:

13 Chunjiang Zhao ${ }^{1,2,3}$ \& Hao Yang 2,3

14 No. 11, Shuguang Garden Middle Road, Haidian District, Beijing, 100097, China

15 Email address: zhaocj@nercita.org.cn \& yangh@nercita.org.cn 
Estimation of maize above-ground biomass based on stem-leaf separation strategy integrated with LiDAR and optical remote sensing data

21

22

23

24

25

26

27

28

29

30

31

32

33

34

35

36

37

38

39

40

41

42

43

44

45

46

47

48

49

50

51

52

53

54

\section{Abstract}

Background. Above-ground biomass (AGB) is an important indicator for effectively assessing crop growth and yield and, in addition, is an important ecological indicator for assessing the efficiency with which crops use light and store carbon in ecosystems. However, most existing methods using optical remote sensing to estimate AGB cannot observe structures below the maize canopy, which may lead to poor estimation accuracy.

Methods. This paper proposes to use the stem-leaf separation strategy integrated with unmanned aerial vehicle LiDAR and multispectral image data to estimate the AGB in maize. First, the correlation matrix was used to screen optimal the LiDAR structural parameters (LSPs) and the spectral vegetation indices (SVIs). According to the screened indicators, the SVIs and the LSPs were subjected to multivariable linear regression (MLR) with the above-ground leaf biomass (AGLB) and above-ground stem biomass (AGSB), respectively. At the same time, all SVIs derived from multispectral data and all LSPs derived from LiDAR data were subjected to partial least squares regression (PLSR) with the AGLB and AGSB, respectively. Finally, the AGB was computed by adding the AGLB and the AGSB, and each was estimated by using the MLR and the PLSR methods, respectively.

Results. The results indicate a strong correlation between the estimated and field-observed AGB using the MLR method $\left(\mathrm{R}^{2}=0.82, \mathrm{RMSE}=79.80 \mathrm{~g} / \mathrm{m}^{2}, \mathrm{NRMSE}=11.12 \%\right)$ and the PLSR method $\left(\mathrm{R}^{2}=0.86, \mathrm{RMSE}=72.28 \mathrm{~g} / \mathrm{m}^{2}, \mathrm{NRMSE}=10.07 \%\right)$. The results indicate that PLSR more accurately estimates AGB than MLR, with $\mathrm{R}^{2}$ increasing by 0.04 , RMSE decreasing by $7.52 \mathrm{~g} / \mathrm{m}^{2}$, and NRMSE decreasing by $1.05 \%$. In addition, the AGB is more accurately estimated by combining LiDAR with multispectral data than LiDAR and multispectral data alone, with $\mathrm{R}^{2}$ increasing by 0.13 and 0.30 , respectively, RMSE decreasing by 22.89 and $54.92 \mathrm{~g} / \mathrm{m}^{2}$, respectively, and NRMSE decreasing by $4.46 \%$ and $7.65 \%$, respectively.

Discussion. This study improves the prediction accuracy of AGB and provides a new guideline for monitoring based on the fusion of multispectral and LiDAR data.

\section{Introduction}

Maize is one of the main food crops today and is planted on a large scale worldwide. The timely and effective access to high-resolution spatial crop-development information provides important guidance for precision agricultural management, which allows the implementation of effective fertilization programs (Cilia et al. 2014; Gracia-Romero et al. 2017; Samborski et al. 2009), 
55

56

57

58

59

60

61

62

63

64

65

66

67

68

69

70

71

72

73

74

75

76

77

78

79

80

81

82

83

84

85

86

87

88

89

90

91

92

93

irrigation measures (Barker et al. 2018; Ma et al. 2018; Maresma et al. 2018), and early production forecasts (Elazab et al. 2016; Kitchen et al. 2003; Vergara-Diaz et al. 2016). Crop above-ground biomass (AGB) is an important indicator for effectively assessing crop growth and yield, and also an important ecological indicator for assessing the efficiency of which crops use light and store carbon in ecosystems.

Accurate monitoring of crop AGB is an effective means to assess farmland productivity. Laboratory destructive methods to estimate biomass mainly involve inefficient and timeconsuming manual sampling measurements, which is difficult to scale up for application to large areas. How to rapidly and accurately estimate the AGB of crops has always been a hot topic ( $\mathrm{Li}$ et al. 2015b; Wang et al. 2017; Zolkos et al. 2013). With its ability to acquire regional- and global-scale information, remote sensing technology has become an effective tool for estimating the AGB of crops over large regions. With the rapid development of remote sensing technology in recent years, multi-source remote sensing data acquired by unmanned aerial vehicle (UAV) fitted with spectral and LiDAR sensors have become widely applied. UAVs have been key to solve different problems in agriculture, which require high-precision crop data, such as crop pest detection (Albetis et al. 2017), crop yield estimation (Zhou et al. 2017), and crop variable measurement (Bendig et al. 2015). This approach allows high-efficiency and dynamic remote sensing monitoring of large areas in a convenient and nondestructive manner and with high throughput. Remote sensing from UAVs has thus become an important part of precision agriculture (Liebisch et al. 2015; Marshall \& Thenkabail 2015; Yang et al. 2017).

In spectroscopy, spectral sensors have been frequently cited as a rapid, nondestructive, and cost-effective tool for estimating agronomic parameters of different crops. With the rapid development of the UAV platform in recent years, the observation scale and timeliness of the spectrometer have rapidly improved (Yang et al. 2018a). Spectral measurements can be used to obtain appropriate spectral indicators from the visible and near-infrared spectral regions to estimate factors that describe crop-canopy growth such as biomass (Liu et al. 2010), leaf area index (Potgieter et al. 2017), and nitrogen content (Fitzgerald et al. 2010). To evaluate the optimal method to estimate crop biomass, many scholars have improved the accuracy of cropbiomass estimates by screening the optimal band or by combining the visible and near-infrared spectral bands (Bendig et al. 2015; Fu et al. 2014; Gnyp et al. 2014; Kross et al. 2015). Other studies have focused on combining crop-growth models with remote sensing data, and assimilating remote sensing data with uncertain input parameters of the crop-growth model, thereby improving the accuracy of crop biomass predictions (Jin et al. 2016; Machwitz et al. 2014). As the spectral resolution of UAV multispectral cameras continues to improve and because the prices are reasonable, this platform has been widely used in vegetation phenotypic monitoring. However, the information obtained by the passive optical sensors mainly comes from the top of the vegetation, so very little information about the vertical structure of the vegetation can be obtained, which reduces the accuracy of the crop-biomass estimate (Wang et al. 2017). 
LiDAR is a stable active remote sensing technology with strong penetration. It works with UAV platforms and provides accurate three-dimensional structural information of the vegetation canopy (Wallace et al. 2014). It provides rapid and nondestructive estimates of structural information, such as height, volume, leaf area index, and leaf area density of vegetation, which can resolve the problem of spectral saturation that occurs in optical remote sensing (Cao et al. 2018; Du et al. 2016; Luo et al. 2018; Tagarakis et al. 2018). Unlike manned aircraft, UAVs are being increasingly used to provide detailed, high-resolution imagery and associated digital elevation models (DEMs) for surface processes and geomorphological research (James \& Robson 2014). LiDAR has been widely used in many scenarios, especially for monitoring forest biomass (Dubayah et al. 2010; Gonzalez de Tanago et al. 2018; Knapp et al. 2018; Li et al. 2017; Li et al. 2014; Nelson et al. 2017; Silva et al. 2017; Stovall et al. 2017). However, LiDAR applications for crop biomass are fewer, and the penetration depth of LiDAR is limited because of the higher density of the crop canopy. A high-density LiDAR point cloud is a necessary condition for detecting crop canopy density and increasing canopy penetration and can be used to directly quantify crop-structure parameters (Christiansen et al. 2018; Eitel et al. 2014; Li et al. 2015a).

In recent years, numerous studies have estimated vegetation biomass by using a combination that includes the three-dimensional structural information of the vegetation and the canopy spectral information (Clark et al. 2011; Laurin et al. 2014; Swatantran et al. 2011). This approach mainly involves (i) merging the LiDAR structural parameters (LSPs) extracted from airborne LiDAR data with the spectral vegetation indices (SVIs) extracted from satellite remote sensing images ( $\mathrm{Li}$ et al. 2015b), (ii) merging the LSPs derived from airborne LiDAR data with the SVIs derived from hyperspectral imagery (Luo et al. 2017; Wang et al. 2017), (iii) merging the LSPs derived from ground-based LiDAR and the SVIs derived from hyperspectral data (Tilly et al. 2015), and (iv) merging the LSPs extracted from vehicle-based LiDAR data with the SVIs extracted from data acquired by active optical sensors (Schaefer \& Lamb 2016). However, previous studies have basically fused LiDAR structural parameters (LSPs) with spectral parameters at the data level to estimate vegetation biomass, and most of the research focuses on forestry. In contrast, few studies have focused on agriculture, and none have estimated the AGB of maize by separating the stem and leaf biomass.

This paper proposes a method to estimate the AGB of maize based on estimates of aboveground leaf biomass (AGLB) and above-ground stem biomass (AGSB) from multispectral data and LiDAR point cloud data, respectively, with both acquired from a UAV platform. By comparing the results of the two types of indicators with those of the AGB estimation model, we evaluate the value of integrating LiDAR data with multispectral data to estimate AGB. This study provides a good guideline for maize-field management based on using multispectral data to estimate leaf biomass and LiDAR point cloud data to estimate stem biomass. The main objectives of this study were (1) to estimate the maize AGB based on a stem-leaf separation strategy integrated with LiDAR and optical remote sensing data; and (2) to compare the 
133 multivariable linear regression (MLR) and partial least squares regression (PLSR) models to

134

135

136

137

138

139

140

141

142

143

144

145

146

147

148

149

150

151

152

153

154

155

156

157

158

159

160

161

162

163

164

165

166

167

168

169

170

171

determine which is most effective for estimating maize AGB.

\section{Materials \& Methods}

\section{Study Area}

The study area was at the Xiaotangshan National Precision Agriculture Research and Demonstration Base of Beijing Academy of Agriculture and Forestry Sciences, Changping District, Beijing, China $\left(40^{\circ} 00^{\prime}-40^{\circ} 21^{\prime} \mathrm{N}, 116^{\circ} 34^{\prime}-117^{\circ} 00^{\prime} \mathrm{E}\right)$. The site has an average altitude of $36 \mathrm{~m}$, its total area is about $1.08 \mathrm{~km}^{2}$, it has an average rainfall of $600 \mathrm{~mm}$, and it is characterized by a typical north temperate semi-humid continental monsoon climate. The main type of crop grown in the area is maize, which is usually sown in late May, flowers in late July, and is harvested in mid-to-late September ( $\mathrm{Li}$ et al. 2015b). The study area $(15 \mathrm{~m} \times 15 \mathrm{~m})$ contained 30 plots $(3 \mathrm{~m} \times 1.25 \mathrm{~m}$ per plot) and was planted with the summer maize variety Jingdan 40 . The field-management measures followed the standard practice for maize production (Figure 1).

[Insert Figure 1 about here]

\section{Field Measurement}

The field measurements were made in the study area on August 28, 2018. The seedlings were treated, and the density of maize plants gradually decreased from north to south. To obtain the AGB of each sample, the data collectors first counted the number of maize plants in each plot. Next, they collected at random from each plot six plants with uniform growth, measured the plant height, and used the average height of the six plants as the measured height for the plot. All samples were then taken back to the laboratory to be oven-dried at $80^{\circ} \mathrm{C}$ until a constant weight was reached, and the dry weight of the maize leaves and stems were recorded separately. The average dry weight (DW) of the six maize plants in each plot was calculated and multiplied by the number $\mathrm{N}$ of corresponding plot plants to obtain the final DW. The DW was divided by the plot area, and the result converted to $\mathrm{g} / \mathrm{m}^{2}$. Finally, the AGB of each sample was measured.

\section{UAV Multispectral Data and Digital Image}

The UAV multispectral data and digital image were collected from 11:00 to 13:00 during sunny and windless weather. The Parrot Sequoia multispectral camera (MicaSense Inc., Seattle, USA) and the DJI FC6310 digital camera were simultaneously fit to the UAV platform of the DJI Phantom 4 Pro (SZ DJI Technology Co., Shenzhen, China) and are characterized by high precision, low weight, and ease of use. The acquired multispectral images contain four spectral channels: green (wavelength $550 \mathrm{~nm}$, bandwidth $40 \mathrm{~nm}$ ), red $(660 \mathrm{~nm}, 40 \mathrm{~nm})$, red edge (735 $\mathrm{nm}, 10 \mathrm{~nm})$, and near-infrared $(790 \mathrm{~nm}, 40 \mathrm{~nm})$. In addition, the DJI FC6310 digital camera is equipped with a 1-inch CMOS sensor with a resolution of 20 megapixels. The UAV flight height was set to $15 \mathrm{~m}$, the speed to $3 \mathrm{~m} / \mathrm{s}$, the forward overlap to $80 \%$, and the side overlap to $70 \%$. The Parrot Sequoia multispectral camera was calibrated before and after the flight test by using a calibrated reflectance panel (MicaSense Inc., Seattle, USA) to minimize error during image capture. 
172

173

174

175

176

177

178

179

180

181

182

183

184

185

186

187

188

189

190

191

192

193

194

195

196

197

198

199

200

201

202

203

204

205

206

207

208

209

210

211

The pre-processing for multispectral image data, including mosaic, radiation calibration, and geometric correction, was handled by the data producer. The Agisoft PhotoScan Professional software (version 1.4.2, Agisoft LCC, St. Petersburg, Russia) was introduced into the multispectral camera's own calibration file to splice the multispectral images. The geometric correction and registration of multispectral images were done based on ground control points, and the spliced multispectral images in four spectral bands were then converted to reflectance by using the QUick Atmospheric Correction tool (QUAC) (Sensor type set to Generic/Unknown Sensor) in ENVI software (version 5.3.1, Esri Inc., Redlands, USA). The ground resolution and reprojection error of the spliced multispectral image are $1.33 \mathrm{~cm} /$ pix and 0.687 pix, respectively. The SVIs were calculated by using the bandmath tool to obtain the SVIs maps. Since these SVIs can respond to different ground objects, we used the bandmath tool to binarize the SVIs maps, and then separated plants from the soil background in these SVIs maps, where the spectral curves of the different AGB soils are shown in Figure 2. In addition, ArcMap (version 10.3.1, Esri Inc., Redlands, USA) was used to create the area of interest (AOI) with separated plant areas and to extract the average vegetation index for each plot.

[Insert Figure 2 about here]

Similar to the multispectral data pre-processing method, digital images with spatial position information were stitched by Agisoft PhotoScan Professional software, and geometric correction and registration of images based on ground control points were then exported to DEM images. The average plant height of each plot was extracted from ArcMap by using the AOI created in the previous step.

\section{UAV LiDAR Point Cloud Data}

The LiDAR data were synchronized with the multispectral image data-acquisition time, and the three-dimensional point cloud data of the study area plants were obtained by the UAV platform DJI M600 Pro (SZ DJI Technology Co., Shenzhen, China) equipped with a RIEGL VUX-1UAV (RIEGL Laser Measurement Systems, Ltd. Horn, Austria) laser scanner (the spot diameter was $0.0075 \mathrm{~m}$, the average ground point spacing was $0.0239 \mathrm{~m}$, the flying height was $15 \mathrm{~m}$, the speed was $3 \mathrm{~m} / \mathrm{s}$, and the maximum scanning angle was $70^{\circ}$ ).

The RiPROCESS software (RIEGL Laser Measurement Systems, Ltd. Horn, Austria) was used for pre-processing, which included the analytical correction of multi-route LiDAR data. Post-processing of the LiDAR data was done by using the LiDAR360 software (version 2.0, GreenValle International, Ltd. California, USA). First, the point cloud data were denoised. Next, the point cloud data of the study area were classified into ground points and non-ground points. The ground point was then normalized by the classified ground point cloud, which eliminates any influence of the terrain. Finally, the DEM and DSM with a high spatial resolution raster of 1 $\mathrm{cm} \times 1 \mathrm{~cm}$ were obtained by using the terrain tool, and the CHM of the study area was calculated as the difference between the DSM and the DEM model. The vegetation height relative to the surface was obtained based on the CHM, and the standardized point cloud structure parameters were calculated from the LiDAR point cloud of the vegetation height. The detailed LiDAR point cloud parameters are shown in Table 1. 
212

213

214

215

216

217

218

219

220

221

222

223

224

225

226

227

228

229

230

231

232

233

234

235

236

237

238

239

240

241

242

243

244

245

246

247

248

249

250

\section{[Insert Table 1 about here]}

\section{Research route}

Research route is shown in Figure 3.

[Insert Figure 3 about here]

\section{Deriving Metrics from Multispectral Data and LiDAR Point Cloud Data}

The physiological properties of vegetation imaged via remote sensing can be extracted by the vegetation indices. The reflectance of a given wavelength provides useful information about leafplant health. The vegetation indices are numbers that are computed from different wavelength reflectances by well-known equations that use the light reflectance of the plants in different bandwidths, especially the green, red, and near infrared (Devia et al. 2019). Vegetation indices have been widely used to estimate biomass by using empirical relationships with biomass (Foody et al. 2003). The more the vegetation grows, the more the red edge redshifts. When the vegetation grows under nutrient stress, the red edge blueshifts. In this study, the sensitivity of multispectral data to the physiological properties of vegetation and the multi-channel advantages of multispectral sensors combine to provide 10 vegetation indices commonly used in the literature to estimate crop biomass. These different vegetation indices were computed (Table 2) and include the Chlorophyll index green (CIgreen), Chlorophyll vegetation index (CVI), Enhanced vegetation index 2 (EVI2), Simple ratio greenness index (GI), Modified triangular vegetation index 2 (MTVI2), Normalized difference vegetation index (NDVI), Normalized green red difference index (NGRDI), Optimized soil adjusted vegetation index (OSAVI), Soil adjusted vegetation index (SAVI) and Simple ratio vegetation index (SRVI).

\section{[Insert Table 2 about here]}

In addition, based on the point cloud structural parameters used in previous studies that focused on estimating crop biomass, we selected four common LSPs: average height (H_mean), maximum height (H_max), height standard deviation (H_sd), and height coefficient of variation (H_cv). Table 3 gives detailed definitions and explanations of these four point cloud structural parameters.

\section{[Insert Table 3 about here]}

\section{Estimation and Verification of Aboveground Biomass}

We propose herein a method for estimating the AGB of maize that uses estimated AGLB and AGSB obtained from multispectral data and LiDAR point cloud data (Figure 4). As opposed to previous methods of predicting AGB by LiDAR and optical remote sensing data in their respective or combined forms, we divided the measurement of maize AGB into two parts: AGLB and AGSB. The method combines the respective advantages of multispectral data and LiDAR point cloud data to measure AGLB and AGSB, respectively. The AGLB of maize was measured by using multispectral data sensitive to the vegetation canopy; the AGSB of maize was measured by using LiDAR point cloud data sensitive to vegetation structure. Finally, the maize AGB was obtained by accumulating the AGLB and AGSB measured in each plot.

[Insert Figure 4 about here] 
251

252

253

254

255

256

257

258

259

260

261

262

263

264

265

266

267

268

269

270

271

272

273

274

275

276

277

278

279

280

281

282

283

284

285

286

In this study, MLR and PLSR were used for maize AGB measurements. First, the correlation between SVIs (CIgreen, CVI, EVI2, GI, MTVI2, NDVI, NGRDI, OSAVI, SAVI, SRVI), LSPs (H_max, H_mean, H_sd, H_cv), and field-measured AGLB and AGSB was used to determine the relationship between the two types of indicators and the above-ground leaf and stem biomass, and the optimal SVIs and LSPs were screened. Next, following previous studies (Bendig et al. 2015), we used MLR methods to estimate crop biomass. Based on the optimized LSPs and SVIs for estimating biomass, a MLR model was then constructed with AGLB and AGSB. We then use all SVIs and LSPs to estimate maize AGB based on the PLSR method. To solve the over-fitting problem of the model, the cross-validation method was used to determine the appropriate number of important factors in the PLSR model. Finally, the optimal method was selected by comparing the effectiveness of MLR and PLSR in estimating corn AGB. In addition, we evaluated the accuracy of the AGB estimation model based on the stem-leaf separation strategy by using LiDAR and multispectral metrics.

\section{Statistical Analysis}

In this study, the correlation coefficient between the predicted biomass and the measured biomass was evaluated by using $\mathrm{R}^{2}$, which measures the relationship between two datasets and describes the proportion of the total variance in the measured data that can be explained by the model [Eq. (1)]. $\mathrm{R}^{2}$ ranges between 0 and 1 with higher values indicating better simulations. The discrepancy between the predicted and measured values of AGB is evaluated based on the root mean square error (RMSE) and normalized root mean square error (NRMSE). The RMSE serves to measure the extent to which the observed value deviates from the measured value and is very sensitive to the error response [Eq. (2)]. The smaller the RMSE, the more accurate the measurement. However, it was difficult to estimate the actual gap between the predicted value and the measured value by RMSE because no specific measurement standard is available. The NRMSE helps to compare datasets or models that use different scales and is usually expressed as a percent, where a lower percent indicates a smaller residual variance and, typically, the model accuracy is excellent if NRMSE is less than 10\%, good if NRMSE is between $10 \%$ and $20 \%$, fair if NRMSE is between $20 \%$ and $30 \%$, and poor if NRMSE exceeds $30 \%$ (Ahmadi et al. 2015) [Eq. (3)]. Therefore, the use of RMSE and NRMSE as indicators for evaluation better reflects the actual accuracy of the model. Meanwhile, one-way analysis of variance (ANOVA) was used to test whether significant differences existed between aboveground biomass at different density levels $(0.01 \leq p \leq 0.05$ indicates a significant difference; $p<0.01$ means an extremely significant difference).

$$
\mathrm{R}^{2}=1-\frac{\sum_{t=0}^{n}\left(\hat{y}_{t}-\bar{y}\right)^{2}}{\sum_{t=1}^{n}\left(y_{t}-\bar{y}\right)^{2}}
$$

Peerj reviewing PDF | (2019:04:36493:2:0:NEW 22 Jul 2019) 
287

288

289

290

291

292

293

294

295

296

297

298

299

300

301

302

303

304

305

306

307

308

309

310

311

312

313

314

315

316

317

318

319

320

321

322

323

324

325

326

In the above formulas, $n$ is the number of samples, $\hat{y}_{t}$ is the values calculated with models, $y_{t}$ is the measured value; $\bar{y}$ is the average value, $y_{\max }$ is the maximum value, and $y_{\min }$ is the minimum value.

\section{Results}

\section{Plant height extracted from digital image and LiDAR data}

The average plant height of each plot was extracted from ArcMap by using the AOI created in the previous step. Subsequently, plant heights of 30 plots were obtained from digital images and LiDAR point cloud data, respectively. Table 4 shows the average, maximum, minimum, and coefficient of variation with plant heights derived from the image, LiDAR point cloud, and ground measured. The spot diameter and the average ground point spacing of the LiDAR point cloud were 0.0075 and $0.0239 \mathrm{~m}$, respectively.

\section{[Insert Table 4 about here]}

\section{Screening for Optimal Variables}

In this study, we constructed the correlation matrix for SVIs and AGB and AGLB and found a significant correlation between different SVIs and AGB and AGLB. Compared with the AGB, the correlation between the AGLB and the vegetation index is higher because the stem of maize cannot be observed in the multispectral image, so the SVIs are more sensitive to the AGLB, as shown in Figure 5(A). Because of the high correlation between the spectral vegetation indices, the multivariate collinearity between indices may be problematic. Therefore, two vegetation indices, NGRDI and SRVI, with the highest correlation coefficient with the corresponding biomass (NGRDI-AGB/AGLB: 0.75/0.85, SRVI-AGB/AGLB: 0.72/0.83) were selected as multivariate variables to prevent overfitting and to reduce the complexity of the model.

Compared with other indices, the NGRDI is very effective for monitoring AGB (Elazab et al. 2016), thereby improving the accuracy of models that estimate AGB. Figure 5(A) shows that the AGLB is more correlated with SVIs than AGB, which further confirms that the SVIs are more sensitive to the AGLB.

Similarly, we constructed a correlation matrix for LSPs, AGB, and AGSB and then found that different LSPs have different sensitivities to AGB and AGSB, as shown in Figure 5(B). Because H_mean and $\mathrm{H} \_$max are significantly correlated with AGB and AGSB (H_mean-AGB/AGSB: 0.84/0.87, H_max-AGB/AGSB: 0.81/0.83), we select these two structural parameters as multivariate variables to construct the MLR model. Figure 5(B) shows that the AGSB is more correlated with LSPs than AGB, which further confirms that the LSPs are more sensitive to the AGSB.

\section{[Insert Figure 5 about here]}

\section{Estimate of Maize Biomass from Multispectral Data}

In this study, we constructed a MLR model by screening multiple-regression variables (NGRDI and SRVI). The AGB was measured from 20 (2/3) samples as the modeling set, and the remaining $10(1 / 3)$ samples were used as validation sets to evaluate the accuracy of the AGB estimate based on multispectral data. The results show that the variance of 0.67 is explained by 
327 the modeling set data $\left(\mathrm{RMSE}=119.03 \mathrm{~g} / \mathrm{m}^{2}, \mathrm{NRMSE}=16.59 \%\right)$ in the AGB measurement, and

328

329

330

331

332

333

334

335

336

337

338

339

340

341

342

343

344

345

346

347

348

349

350

351

352

353

354

355

356

357

358

359

360

361

362

363

364

365

the variance of 0.18 is explained by the validation set data $\left(\mathrm{RMSE}=136.76 \mathrm{~g} / \mathrm{m}^{2}, \mathrm{NRMSE}=\right.$ $28.51 \%$ ) in the AGB measurement. Figure 6(A) shows a scatterplot of field-observed biomass versus estimated biomass using two vegetation indices $\left(\mathrm{R}^{2}=0.56, \mathrm{RMSE}=125.38 \mathrm{~g} / \mathrm{m}^{2}\right.$, NRMSE $=17.47 \%$ ), and introduce 95\% confidence level (Wang et al. 2018a). In addition, we constructed a PLSR model by all SVIs, with 20 (2/3) samples as the modeling set; the remaining $10(1 / 3)$ samples were used as validation sets to evaluate the accuracy with which the AGB is estimated based on multispectral data. At the same time, two important factors in the PLSR model were determined by using the cross-validation method. The results show that the variance of 0.67 is explained by the modeling set data (RMSE $\left.=118.40 \mathrm{~g} / \mathrm{m}^{2}, \mathrm{NRMSE}=16.49 \%\right)$ in the AGB measurement, and the variance of 0.32 is explained by the validation set data (RMSE $=$ $143.18 \mathrm{~g} / \mathrm{m}^{2}, \mathrm{NRMSE}=29.84 \%$ ) in the AGB measurement. Figure 6(B) shows a scatterplot of field-observed biomass versus estimated biomass using all vegetation indices $\left(\mathrm{R}^{2}=0.56\right.$, $\mathrm{RMSE}$ $\left.=127.20 \mathrm{~g} / \mathrm{m}^{2}, \mathrm{NRMSE}=17.72 \%\right)$.

\section{[Insert Figure 6 about here]}

The results show a low correlation between field-observed biomass and estimated biomass, which is tentatively attributed to the stem of maize not appearing in the multispectral images and the maize AGLB only accounting for about $25 \%$ of the AGB. Meanwhile, no significant difference appears in the accuracy of the AGB-SVIs estimation model constructed by the MLR and PLSR methods. Thus, the ability to predict AGB by using multispectral data is limited.

\section{Estimate of Maize Biomass from LiDAR Data}

In this study, we constructed a MLR model by screening multiple-regression variables (H_mean and H_max) and measured AGB, with 20 (2/3) samples as the modeling set and the remaining 10 $(1 / 3)$ samples serving as validation sets to evaluate the accuracy with which the AGB is estimated based on LiDAR data. The results show that the variance of 0.77 is explained by the modeling set data $\left(\mathrm{RMSE}=98.81 \mathrm{~g} / \mathrm{m}^{2}, \mathrm{NRMSE}=13.77 \%\right)$ in the AGB measurement, and the variance of 0.53 is explained by the validation set data $\left(\mathrm{RMSE}=91.04 \mathrm{~g} / \mathrm{m}^{2}, \mathrm{NRMSE}=18.98 \%\right.$ ) in the AGB measurement. Figure 7(A) shows a scatterplot of the field-observed AGB versus the AGB estimated by using two LSPs $\left(\mathrm{R}^{2}=0.73, \mathrm{RMSE}=96.29 \mathrm{~g} / \mathrm{m}^{2}, \mathrm{NRMSE}=13.41 \%\right)$. In addition, we constructed a PLSR model by all LSPs, with $20(2 / 3)$ samples as the modeling set and the remaining $10(1 / 3)$ samples serving as validation sets to evaluate the accuracy with which the AGB is estimated based on LiDAR data. At the same time, two important factors in the PLSR model are determined by using the cross-validation method. The results show that the variance of 0.76 is explained by the modeling set data $\left(\mathrm{RMSE}=99.92 \mathrm{~g} / \mathrm{m}^{2}, \mathrm{NRMSE}=13.92 \%\right)$ in the AGB measurement, and the variance of 0.66 is explained by the validation set data (RMSE $=84.85 \mathrm{~g} / \mathrm{m}^{2}, \mathrm{NRMSE}=17.68 \%$ ) in the AGB measurement. Figure 7(B) shows a scatterplot of the field-observed AGB versus the AGB estimated by using two LSPs $\left(\mathrm{R}^{2}=0.74\right.$, $\mathrm{RMSE}=$ $95.17 \mathrm{~g} / \mathrm{m}^{2}, \mathrm{NRMSE}=13.26 \%$ ).

[Insert Figure 7 about here]

Peer) reviewing PDF | (2019:04:36493:2:0:NEW 22 Jul 2019) 
366

367

368

369

370

371

372

373

374

375

376

377

378

379

380

381

382

383

384

385

386

387

388

389

390

391

392

393

394

395

396

397

398

399

400

401

402

403

404

The accuracy of AGB estimate based on LiDAR data clearly exceeds that of the AGB estimate based on multispectral data: $\mathrm{R}^{2}$ increases by $0.17 \sim 0.18$, RMSE decreases by $29.08 \sim 32.03$ $\mathrm{g} / \mathrm{m}^{2}$, NRMSE decreases by $4.36 \sim 4.46 \%$, and the estimated biomass is consistent with the fieldobserved biomass. These results further confirm a strong correlation between the LSPs and the AGB. The MLR and PLSR model constructed from the LSPs can better estimate the AGB of maize, which is consistent with the results of previous studies (Wang et al. 2017).

\section{Estimate of Maize AGB from Fusion of Multispectral and LiDAR Data Compared with Multispectral and LiDAR Data Only}

In this study, because of the sensitivity of multispectral data to AGLB and of LiDAR data to AGSB, we propose a method for estimating maize biomass in which the AGLB and AGSB are estimated based on the multispectral data and LiDAR data, respectively. According to the screened indicators, the SVIs derived from multispectral data and the LSPs derived from LiDAR data were subjected to MLR with the AGLB and AGSB, respectively. At the same time, all SVIs derived from multispectral data and all LSPs derived from LiDAR data were subjected to PLSR with the AGLB and AGSB, respectively. Similarly, 20 (2/3) samples were used as the modeling set, and the remaining $10(1 / 3)$ samples were used as the verification set (Figures 8 and 9 ).

The results show that the MLR model constructed by SVIs and AGLB with the variance of 0.77 is explained by the modeling set data (RMSE $=27.39 \mathrm{~g} / \mathrm{m}^{2}, \mathrm{NRMSE}=13.84 \%$ ), and the variance of 0.57 is explained by the validation set data $\left(\mathrm{RMSE}=26.15 \mathrm{~g} / \mathrm{m}^{2}, \mathrm{NRMSE}=\right.$ 25.78\%). Figure 8(A) shows a scatterplot of the field-observed AGLB versus the AGLB estimated by using two vegetation indices $\left(\mathrm{R}^{2}=0.72\right.$, RMSE $\left.=26.98 \mathrm{~g} / \mathrm{m}^{2}, \mathrm{NRMSE}=13.63 \%\right)$. Next, the results show that the MLR model constructed by the LSPs and AGSB, with a variance of 0.81 , is explained by the modeling set data (RMSE $=66.46 \mathrm{~g} / \mathrm{m}^{2}, \mathrm{NRMSE}=12.79 \%$ ), and the variance of 0.61 is explained by the validation set data $\left(\mathrm{RMSE}=64.92 \mathrm{~g} / \mathrm{m}^{2}, \mathrm{NRMSE}=\right.$ $17.16 \%)$. Figure 8(B) shows a scatterplot of the field-observed AGSB versus the AGSB estimated by using two LSPs $\left(\mathrm{R}^{2}=0.77, \mathrm{RMSE}=65.95 \mathrm{~g} / \mathrm{m}^{2}\right.$, NRMSE $\left.=12.68 \%\right)$.

[Insert Figure 8 about here]

In addition, two important factors in the PLSR model are determined by using the crossvalidation method. The results show that the PLSR model constructed by SVIs and AGLB with the variance of 0.78 is explained by the modeling set data $\left(\mathrm{RMSE}=26.55 \mathrm{~g} / \mathrm{m}^{2}, \mathrm{NRMSE}=\right.$ $13.41 \%$ ), and the variance of 0.70 is explained by the validation set data (RMSE $=29.46 \mathrm{~g} / \mathrm{m}^{2}$, NRMSE $=29.04 \%$ ). Figure 9(A) shows a scatterplot of the field-observed AGLB versus the AGLB estimated by using all vegetation indices $\left(\mathrm{R}^{2}=0.73, \mathrm{RMSE}=27.56 \mathrm{~g} / \mathrm{m}^{2}, \mathrm{NRMSE}=\right.$ 13.92\%). Next, the results show that the PLSR model constructed by the LSPs and AGSB, with a variance of 0.80 , is explained by the modeling set data $\left(\mathrm{RMSE}=68.23 \mathrm{~g} / \mathrm{m}^{2}, \mathrm{NRMSE}=\right.$ $13.12 \%$ ), and the variance of 0.75 is explained by the validation set data (RMSE $=59.02 \mathrm{~g} / \mathrm{m}^{2}$, NRMSE $=15.60 \%$ ). Figure 9(B) shows a scatterplot of the field-observed AGSB versus the AGSB estimated by using all LSPs $\left(\mathrm{R}^{2}=0.78, \mathrm{RMSE}=65.31 \mathrm{~g} / \mathrm{m}^{2}, \mathrm{NRMSE}=12.57 \%\right)$.

\section{[Insert Figure 9 about here]}


405

406

407

408

409

410

411

412

413

414

415

416

417

418

419

420

421

422

423

424

425

426

427

428

429

430

431

432

433

434

435

436

437

438

439

440

441

442

443

444

Overall, compared with the AGB, the multispectral data estimate of the AGLB leads to an increase in $\mathrm{R}^{2}$ of $0.16 \sim 0.17$, which means that the multispectral data are more sensitive to the AGLB. In addition, the LiDAR-data estimate of the AGSB leads to an increase in $\mathrm{R}^{2}$ of $0.04 \sim$ 0.05 , which means that the LiDAR data are more sensitive to the AGSB. We then estimated the AGB by accumulating the estimated AGLB and the estimated AGSB using MLR and PLSR methods, respectively, and a linear regression was constructed by using the field-observed AGB and the estimated AGB. The results show that the variance of 0.82 is explained by the synergistic use of multispectral and LiDAR data $\left(\mathrm{RMSE}=79.80 \mathrm{~g} / \mathrm{m}^{2}, \mathrm{NRMSE}=11.12 \%\right)$ in the AGB measurement using MLR method [Figure 10(A)]; and the variance of 0.86 is explained by the synergistic use of multispectral and LiDAR data $\left(\mathrm{RMSE}=72.28 \mathrm{~g} / \mathrm{m}^{2}, \mathrm{NRMSE}=10.07 \%\right)$ in the AGB measurement using PLSR method [Figure 10(B)].

\section{[Insert Figure 10 about here]}

The study found that PLSR is more accurate for AGB estimation than MLR, with $\mathrm{R}^{2}$ increasing by 0.04 , RMSE decreasing by $7.52 \mathrm{~g} / \mathrm{m}^{2}$, and NRMSE decreasing by $1.05 \%$. Instead of using the SVIs and LSPs separately to estimate AGB, this study estimates the AGB by using the AGLB and AGSB of maize estimated from multispectral and LiDAR data, respectively. By merging the estimates based on LiDAR and multispectral data, the method improves the accuracy with which the maize AGB is estimated. This study thus gives good results that indicate a high potential for estimating maize AGB based on stem-leaf separation strategy (Table 5).

[Insert Table 5 about here]

To illustrate the difference in AGB between different densities, the results of the ANOVA analysis show that the $\mathrm{p}$ value is less than 0.001 , which indicates that there were statistical differences between the groups at different density levels. We therefore do a multiple comparative analysis in the discussion.

\section{Discussion}

Accurate monitoring of maize AGB can provide valuable guidance for agricultural production. In this study, MLR and PLSR were used for maize AGB measurements. To avoid the multicollinearity and over-fitting problems of the MLR model, all the predictors are screened in advance to obtain the optimal variables. The obvious advantage of the MLR method is that it is highly interpretable, and its standardized partial regression coefficient determines the strength of independent variables versus dependent variables (Han et al. 2019). Compared with the traditional MLR model, however, the PLSR model concentrates on the characteristics of principal component regression (PCR) and MLR methods in the modeling process (Geladi \& Kowalski 1986). Therefore, the PLSR model can allow regression modeling under the condition that the independent variables have multiple collinearities to find latent structures in a large number of variables by reducing the number of variables to a few noncorrelated principal components (Cho et al. 2007; Naesset et al. 2005). Although the PLSR model has higher prediction accuracy, both methods achieve acceptable accuracy. To obtain the optimal training model, sufficient samples are necessary. Considering that the actual sample size of this study is

Peer) reviewing PDF | (2019:04:36493:2:0:NEW 22 Jul 2019) 
445 relatively small, no attempt was made to use these methods, such as artificial neural network 446 (ANN) (Vahedi 2016; Xie et al. 2009; Yang et al. 2018b) or support vector machine (SVM) 447 (Clevers et al. 2007; Marabel \& Alvarez-Taboada 2013). In fact, we emphasize herein the idea of 448 stem-leaf separation modeling. The application of this idea in the above machine learning model will be realized after the sample is expanded in future experiments.

452

453

454

455

456

457

458

459

460

461

462

463

464

465

466

467

468

469

470

471

472

473

474

475

476

477

478

479

480

481

482

483

484

Plant height is an important morphological and phenotypic indicator that directly indicates the overall growth of plants and predicts crop biomass and yield. Therefore, obtaining high-precision vegetation height is an important factor for accurately estimating vegetation biomass (Wang et al. 2018b). In previous studies, many scholars used digital and LiDAR data to estimate vegetation height (Jensen \& Mathews 2016; Madec et al. 2017; Wallace et al. 2016). In the present study, the plant height was determined based on digital and LiDAR point cloud data, and the results were verified by comparison with the measured plant height on artificial ground. The results show that, compared with the LiDAR point cloud data, the height parameters of the extracted digital image contain some outliers, which differ significantly from the values measured on the ground. However, the height parameters derived from the canopy threedimensional dense point cloud data acquired by the LiDAR sensor are strongly consistent with the values measured on the ground, and the accuracy of the height measurement is greatly improved compared with the digital image (Figure 11). Therefore, compared with digital images, the use of the LiDAR point cloud data leads to accurate estimates of plant height.

\section{[Insert Figure 11 about here]}

Although many studies have estimated crop biomass based on airborne spectral data (Bendig et al. 2015; Fu et al. 2014; Gnyp et al. 2014; Kross et al. 2015; Liu et al. 2010), multispectral data have only limited ability to estimate crop biomass. In fact, because airborne multispectral images only observe the upper canopy leaves, the structure below the canopy is not monitored when the vegetation density is high, resulting in limited information on the vertical structure of the observed vegetation. Moreover, when the crop density in the observation area is large, the spectral signal from the spectral sensor saturates (Baret \& Guyot 1991; Turner et al. 1999). In addition, we find that the percent of AGLB and AGSB in the AGB is $13.77 \% \sim 27.84 \%$ and $72.16 \% \sim 86.23 \%$, respectively (Figure 12). These results show that the AGLB accounts for no more than $30 \%$ of the AGB. Therefore, since it is difficult to obtain the vertical structure information of the crop from the spectral data, estimating the AGB of the crop based on the spectral data alone may result in less accurate estimates of crop biomass (Wang et al. 2017).

\section{[Insert Figure 12 about here]}

In addition, from the one-way ANOVA, since the $p$ value is far less than 0.05 , it can be inferred that, when the plant density differs between plots, the mean value of the AGB differs significantly. Second, based on the multiple comparison results and the homogeneity of the variance, we conclude that the mean difference in AGB is statistically significant when the $p$ value is less than 0.05 , when the density F $(1 \sim 10)$ is compared with the density $\mathrm{G}(11 \sim 20)$, the density $\mathrm{F}$ is compared with the density $\mathrm{H}(21 \sim 30)$, the density $\mathrm{F}$ is compared with the density I $(>30)$, and the density $\mathrm{G}$ is compared with the density I. However, when the density $\mathrm{H}$ is

PeerJ reviewing PDF | (2019:04:36493:2:0:NEW 22 Jul 2019) 
485 compared with the density $\mathrm{G}$ and the density $\mathrm{H}$ is compared with the density $\mathrm{I}$, the mean

486 difference in AGB is not statistically significant. This may increase the density of the plants in

487 the given plot. And plant height also increases due to competitive-growth effects between plants.

488 But the overall biomass of the plot does not differ significantly from the biomass of the density

$489 \mathrm{G}$ and I, resulting in no statistical significance between density H and G, I (Table 6).

$490 \quad$ [Insert Table 6 about here]

491 Conclusions

492 Remote sensing UAV platforms equipped with LiDAR and multispectral sensors offer the

493 advantages of flexible operation, convenient data acquisition, and high spatial resolution. In this

494 study, we use the LiDAR and multispectral data acquired from the UAV platform to evaluate

495 their use for estimating the AGB of maize. This paper proposes the stem-leaf separation strategy

496 integrated with unmanned aerial vehicle LiDAR and multispectral image data to estimate the

497 AGB of maize.

498 According to the screened indicators, the SVIs derived from multispectral data and the LSPs

499 derived from LiDAR data were subjected to MLR with the AGLB and AGSB, respectively. At

500 the same time, all SVIs derived from multispectral data and all LSPs derived from LiDAR data

501 were subjected to PLSR with the AGLB and AGSB, respectively. Next, the estimated values of

502 above-ground leaf biomass and above-ground stem biomass were added to a single estimation

503 for AGB. The results indicate a strong correlation between the estimated and field-observed of

504 above-ground biomass using the MLR method $\left(\mathrm{R}^{2}=0.82, \mathrm{RMSE}=79.80 \mathrm{~g} / \mathrm{m}^{2}, \mathrm{NRMSE}=\right.$

$50511.12 \%)$ and the PLSR method $\left(\mathrm{R}^{2}=0.86, \mathrm{RMSE}=72.28 \mathrm{~g} / \mathrm{m}^{2}, \mathrm{NRMSE}=10.07 \%\right)$. The results

506 show that PLSR is more accurate for estimating AGB than MLR, with $\mathrm{R}^{2}$ increasing by 0.04 ,

507 RMSE decreasing by $7.52 \mathrm{~g} / \mathrm{m}^{2}$, and NRMSE decreasing by $1.05 \%$. In addition, the AGB is

508 more accurately estimated by combining LiDAR with multispectral data than LiDAR and

509 multispectral data alone, with $\mathrm{R}^{2}$ increasing by 0.13 and 0.30 , respectively, RMSE decreasing by

51022.89 and $54.92 \mathrm{~g} / \mathrm{m}^{2}$, respectively, and NRMSE decreasing by $4.46 \%$ and $7.65 \%$, respectively.

511 This result reflects a significant improvement in the accuracy of the estimated AGB of maize.

512 Thus, the findings of this study lead us to conclude that this technology would allow for the

513 convenient surveillance of maize to observe growth trends and could therefore provide guidance

514 in agriculture management decisions. Although the statistical tests showed the effectiveness of

515 the stem-leaf separation strategy, the scale of maize plants tested in this study is relatively small.

516 Out next study will therefore assess different scales of maize planting to determine the

517 effectiveness of the proposed method in real production scenarios.

518

519 Acknowledgements

520 Thanks to Weiguo Li, Hong Chang, Dong Han, Chuanlong Ding, Yulong Wang, Bo Zhang, Rui

521 Chen and Zhuangzhi Yuan for the field data collection and farmland management. Thanks to

522 Hao Yang, Liang Han and Zhenhai Li for their help in my research and writing of this paper. We

523 are grateful to the anonymous reviewers for their helpful comments and suggestions on the

524 manuscript. 


\section{Competing Interests}

526 The authors declare that they have no competing interests.

527

528

529

530

531

532

533

534

535

536

537

538

539

540

541

542

543

544

545

546

547

548

549

550

551

552

553

554

555

556

557

558

559

560

561

562

563

564

565

566

567

568

569

570

571

572

573

574

\section{References}

Ahmadi SH, Mosallaeepour E, Kamgar-Haghighi AA, and Sepaskhah AR. 2015. Modeling Maize Yield and Soil Water Content with AquaCrop Under Full and Deficit Irrigation Managements. Water Resources Management 29:2837-2853. 10.1007/s11269-015-0973-3

Albetis J, Duthoit S, Guttler F, Jacquin A, Goulard M, Poilvé H, Feret J-B, and Dedieu G. 2017. Detection of Flavescence dorée Grapevine Disease Using Unmanned Aerial Vehicle (UAV) Multispectral Imagery.

Baret F, and Guyot G. 1991. Potentials and limits of vegetation indices for LAI and APAR assessment. Remote Sensing of Environment 35:161-173. https://doi.org/10.1016/00344257(91)90009-U

Barker JB, Heeren DM, Neale CMU, and Rudnick DR. 2018. Evaluation of variable rate irrigation using a remote-sensing-based model. Agricultural Water Management 203:63-74. 10.1016/j.agwat.2015.02.022

Bendig J, Yu K, Aasen H, Bolten A, Bennertz S, Broscheit J, Gnyp ML, and Bareth G. 2015. Combining UAV-based plant height from crop surface models, visible, and near infrared vegetation indices for biomass monitoring in barley. International Journal of Applied Earth Observation and Geoinformation 39:79-87. https://doi.org/10.1016/j.jag.2015.02.012

Cao LD, Pan JJ, Li RJ, Li JL, and Li ZF. 2018. Integrating Airborne LiDAR and Optical Data to Estimate Forest Aboveground Biomass in Arid and Semi-Arid Regions of China. Remote Sensing 10. 10.3390/rs10040532

Cho MA, Skidmore A, Corsi F, van Wieren SE, and Sobhan I. 2007. Estimation of green grass/herb biomass from airborne hyperspectral imagery using spectral indices and partial least squares regression. International Journal of Applied Earth Observation and Geoinformation 9:414-424. 10.1016/j.jag.2007.02.001

Christiansen MP, Laursen M, Jørgensen R, Skovsen S, and Gislum R. 2018. Ground vehicle mapping of fields using LiDAR to enable prediction of crop biomass.

Cilia C, Panigada C, Rossini M, Meroni M, Busetto L, Amaducci S, Boschetti M, Picchi V, and Colombo R. 2014. Nitrogen Status Assessment for Variable Rate Fertilization in Maize through Hyperspectral Imagery. Remote Sensing 6:6549-6565. 10.3390/rs6076549

Clark ML, Roberts DA, Ewel JJ, and Clark DB. 2011. Estimation of tropical rain forest aboveground biomass with small-footprint lidar and hyperspectral sensors. Remote Sensing of Environment 115:2931-2942. 10.1016/j.rse.2010.08.029

Clevers JGPW, van der Heijden GWAM, Verzakov S, and Schaepman ME. 2007. Estimating grassland Biomass using SVM band shaving of hyperspectral data. Photogrammetric Engineering and Remote Sensing 73:1141-1148. Doi 10.14358/Pers.73.10.1141

Datt B, McVicar TR, Van Niel TG, Jupp DLB, and Pearlman JS. 2003. Preprocessing EO-1 Hyperion hyperspectral data to support the application of agricultural indexes. leee Transactions on Geoscience and Remote Sensing 41:1246-1259. 10.1109/Tgrs.2003.813206

Devia CA, Rojas JP, Petro E, Martinez C, Mondragon IF, Patino D, Rebolledo MC, and Colorado J. 2019. High-Throughput Biomass Estimation in Rice Crops Using UAV Multispectral Imagery. Journal of Intelligent \& Robotic Systems. 10.1007/s10846-019-010015

Du L, Gong W, Shi S, Yang P, Sun J, Zhu B, and Song SL. 2016. Estimation of rice leaf nitrogen contents based on hyperspectral LIDAR. International Journal of Applied Earth Observation and Geoinformation 44:136-143. 10.1016/j.jag.2015.08.008

Dubayah RO, Sheldon SL, Clark DB, Hofton MA, Blair JB, Hurtt GC, and Chazdon RL. 2010. Estimation of tropical forest height and biomass dynamics using lidar remote sensing at $\mathrm{La}$

Peer] reviewing PDF | (2019:04:36493:2:0:NEW 22 Jul 2019) 
575

576

577

578

579

580

581

582

583

584

585

586

587

588

589

590

591

592

593

594

595

596

597

598

599

600

601

602

603

604

605

606

607

608

609

610

611

612

613

614

615

616

617

618

619

620

621

622

623

624

Selva, Costa Rica. Journal of Geophysical Research-Biogeosciences 115. 10.1029/2009jg000933

Eitel JUH, Magney TS, Vierling LA, Brown TT, and Huggins DR. 2014. LiDAR based biomass and crop nitrogen estimates for rapid, non-destructive assessment of wheat nitrogen status. Field Crops Research 159:21-32. 10.1016/j.fcr.2014.01.008

Elazab A, Ordonez RA, Savin R, Slafer GA, and Araus JL. 2016. Detecting interactive effects of $\mathrm{N}$ fertilization and heat stress on maize productivity by remote sensing techniques. European Journal of Agronomy 73:11-24. 10.1016/j.eja.2015.11.010

Fitzgerald G, Rodriguez D, and O'Leary G. 2010. Measuring and predicting canopy nitrogen nutrition in wheat using a spectral index-The canopy chlorophyll content index ( $\mathrm{CCCl})$. Field Crops Research 116:318-324. https://doi.org/10.1016/j.fcr.2010.01.010

Foody GM, Boyd DS, and Cutler MEJ. 2003. Predictive relations of tropical forest biomass from Landsat TM data and their transferability between regions. Remote Sensing of Environment 85:463-474. 10.1016/S0034-4257(03)00039-7

Fu YY, Yang GJ, Wang JH, Song XY, and Feng HK. 2014. Winter wheat biomass estimation based on spectral indices, band depth analysis and partial least squares regression using hyperspectral measurements. Computers and Electronics in Agriculture 100:51-59. 10.1016/j.compag.2013.10.010

Geladi P, and Kowalski BR. 1986. Partial least-squares regression: a tutorial. Analytica Chimica Acta 185:1-17. https://doi.org/10.1016/0003-2670(86)80028-9

Gitelson AA, Vina A, Arkebauer TJ, Rundquist DC, Keydan G, and Leavitt B. 2003. Remote estimation of leaf area index and green leaf biomass in maize canopies. Geophysical Research Letters 30. 10.1029/2002gl016450

Gnyp ML, Miao YX, Yuan F, Ustin SL, Yu K, Yao YK, Huang SY, and Bareth G. 2014. Hyperspectral canopy sensing of paddy rice aboveground biomass at different growth stages. Field Crops Research 155:42-55. 10.1016/j.fcr.2013.09.023

Gonzalez de Tanago J, Lau A, Bartholomeus H, Herold M, Avitabile V, Raumonen P, Martius C, Goodman RC, Disney M, Manuri S, Burt A, and Calders K. 2018. Estimation of above-ground biomass of large tropical trees with terrestrial LiDAR. 9:223-234. doi:10.1111/2041210X.12904

Gracia-Romero A, Kefauver SC, Vergara-Diaz O, Zaman-Allah MA, Prasanna BM, Cairns JE, and Araus JL. 2017. Comparative Performance of Ground vs. Aerially Assessed RGB and Multispectral Indices for Early-Growth Evaluation of Maize Performance under Phosphorus Fertilization. Frontiers in Plant Science 8. 10.3389/fpls.2017.02004

Haboudane D, Miller JR, Pattey E, Zarco-Tejada PJ, and Strachan IB. 2004. Hyperspectral vegetation indices and novel algorithms for predicting green LAI of crop canopies: Modeling and validation in the context of precision agriculture. Remote Sensing of Environment 90:337-352. 10.1016/j.rse.2003.12.013

Han L, Yang GJ, Dai HY, Xu B, Yang H, Feng HK, Li ZH, and Yang XD. 2019. Modeling maize above-ground biomass based on machine learning approaches using UAV remote-sensing data. Plant Methods 15. ARTN 10

10.1186/s13007-019-0394-Z

Huete A. 1988. Huete, A. R. A soil-adjusted vegetation index (SAVI). Remote Sensing of Environment.

James MR, and Robson S. 2014. Mitigating systematic error in topographic models derived from UAV and ground-based image networks. Earth Surface Processes and Landforms 39:1413-1420. 10.1002/esp.3609

Jensen JLR, and Mathews AJ. 2016. Assessment of Image-Based Point Cloud Products to Generate a Bare Earth Surface and Estimate Canopy Heights in a Woodland Ecosystem. Remote Sensing 8. 10.3390/rs8010050

Peer) reviewing PDF | (2019:04:36493:2:0:NEW 22 Jul 2019) 
625

626

627

628

629

630

631

632

633

634

635

636

637

638

639

640

641

642

643

644

645

646

647

648

649

650

651

652

653

654

655

656

657

658

659

660

661

662

663

664

665

666

667

668

669

670

671

672

673

674

Jiang ZY, Huete AR, Didan K, and Miura T. 2008. Development of a two-band enhanced vegetation index without a blue band. Remote Sensing of Environment 112:3833-3845. 10.1016/j.rse.2008.06.006

Jin XL, Kumar L, Li ZH, Xu XG, Yang GJ, and Wang JH. 2016. Estimation of Winter Wheat Biomass and Yield by Combining the AquaCrop Model and Field Hyperspectral Data. Remote Sensing 8. 10.3390/rs8120972

Kitchen NR, Drummond ST, Lund ED, Sudduth KA, and Buchleiter GW. 2003. Soil electrical conductivity and topography related to yield for three contrasting soil-crop systems. Agronomy Journal 95:483-495. DOI 10.2134/agronj2003.0483

Knapp N, Fischer R, and Huth A. 2018. Linking lidar and forest modeling to assess biomass estimation across scales and disturbance states. Remote Sensing of Environment 205:199209. 10.1016/j.rse.2017.11.018

Kross A, McNairn H, Lapen D, Sunohara M, and Champagne C. 2015. Assessment of RapidEye vegetation indices for estimation of leaf area index and biomass in corn and soybean crops. International Journal of Applied Earth Observation and Geoinformation 34:235-248. 10.1016/j.jag.2014.08.002

Laurin GV, Chen Q, Lindsell JA, Coomes DA, Del Frate F, Guerriero L, Pirotti F, and Valentini R. 2014. Above ground biomass estimation in an African tropical forest with lidar and hyperspectral data. Isprs Journal of Photogrammetry and Remote Sensing 89:49-58. 10.1016/j.isprsjprs.2014.01.001

Li AH, Dhakal S, Glenn NF, Spaete LP, Shinneman DJ, Pilliod DS, Arkle RS, and Mcllroy SK. 2017. Lidar Aboveground Vegetation Biomass Estimates in Shrublands: Prediction, Uncertainties and Application to Coarser Scales. Remote Sensing 9. 10.3390/rs9090903

Li W, Niu Z, Gao S, Huang N, and Chen HY. 2014. Correlating the Horizontal and Vertical Distribution of LiDAR Point Clouds with Components of Biomass in a Picea crassifolia Forest. Forests 5:1910-1930. 10.3390/f5081910

Li W, Niu Z, Huang N, Wang C, Gao S, and Wu CY. 2015a. Airborne LiDAR technique for estimating biomass components of maize: A case study in Zhangye City, Northwest China. Ecological Indicators 57:486-496. 10.1016/j.ecolind.2015.04.016

Li W, Niu Z, Wang C, Huang WJ, Chen HY, Gao S, Li D, and Muhammad S. 2015b. Combined Use of Airborne LiDAR and Satellite GF-1 Data to Estimate Leaf Area Index, Height, and Aboveground Biomass of Maize During Peak Growing Season. leee Journal of Selected Topics in Applied Earth Observations and Remote Sensing 8:4489-4501. 10.1109/Jstars.2015.2496358

Liebisch F, Kirchgessner N, Schneider D, Walter A, and Hund A. 2015. Remote, aerial phenotyping of maize traits with a mobile multi-sensor approach. Plant Methods 11. 10.1186/s13007-015-0048-8

Liu JG, Pattey E, Miller JR, McNairn H, Smith A, and Hu BX. 2010. Estimating crop stresses, aboveground dry biomass and yield of corn using multi-temporal optical data combined with a radiation use efficiency model. Remote Sensing of Environment 114:1167-1177. 10.1016/j.rse.2010.01.004

Luo SZ, Chen JM, Wang C, Gonsamo A, Xi XH, Lin Y, Qian MJ, Peng DL, Nie S, and Qin HM. 2018. Comparative Performances of Airborne LiDAR Height and Intensity Data for Leaf Area Index Estimation. leee Journal of Selected Topics in Applied Earth Observations and Remote Sensing 11:300-310. 10.1109/Jstars.2017.2765890

Luo SZ, Wang C, Xi XH, Pan FF, Peng DL, Zou J, Nie S, and Qin HM. 2017. Fusion of airborne LiDAR data and hyperspectral imagery for aboveground and belowground forest biomass estimation. Ecological Indicators 73:378-387. 10.1016/j.ecolind.2016.10.001

Ma YF, Liu SM, Song LS, Xu ZW, Liu YL, Xu TR, and Zhu ZL. 2018. Estimation of daily evapotranspiration and irrigation water efficiency at a Landsat-like scale for an arid irrigation

Peer] reviewing PDF | (2019:04:36493:2:0:NEW 22 Jul 2019) 
675

676

677

678

679

680

681

682

683

684

685

686

687

688

689

690

691

692

693

694

695

696

697

698

699

700

701

702

703

704

705

706

707

708

709

710

711

712

713

714

715

716

717

718

719

720

721

722

723

area using multi-source remote sensing data. Remote Sensing of Environment 216:715-734. 10.1016/j.rse.2018.07.019

Machwitz M, Giustarini L, Bossung C, Frantz D, Schlerf M, Lilienthal H, Wandera L, Matgen P, Hoffmann L, and Udelhoven T. 2014. Enhanced biomass prediction by assimilating satellite data into a crop growth model. Environmental Modelling \& Software 62:437-453. 10.1016/j.envsoft.2014.08.010

Madec S, Baret F, de Solan B, Thomas S, Dutartre D, Jezequel S, Hemmerle M, Colombeau G, and Comar A. 2017. High-Throughput Phenotyping of Plant Height: Comparing Unmanned Aerial Vehicles and Ground LiDAR Estimates. Frontiers in Plant Science 8. 10.3389/fpls.2017.02002

Marabel M, and Alvarez-Taboada F. 2013. Spectroscopic Determination of Aboveground Biomass in Grasslands Using Spectral Transformations, Support Vector Machine and Partial Least Squares Regression. Sensors 13:10027-10051. 10.3390/s130810027

Maresma A, Lloveras J, and Martinez-Casasnovas JA. 2018. Use of Multispectral Airborne Images to Improve In-Season Nitrogen Management, Predict Grain Yield and Estimate Economic Return of Maize in Irrigated High Yielding Environments. Remote Sensing 10. 10.3390/rs10040543

Marshall M, and Thenkabail P. 2015. Developing in situ Non-Destructive Estimates of Crop Biomass to Address Issues of Scale in Remote Sensing. Remote Sensing 7:808-835. 10.3390/rs70100808

Naesset E, Bollandsas OM, and Gobakken T. 2005. Comparing regression methods in estimation of biophysical properties of forest stands from two different inventories using laser scanner data. Remote Sensing of Environment 94:541-553. 10.1016/j.rse.2004.11.010

Nelson R, Margolis H, Montesano P, Sun GQ, Cook B, Corp L, Andersen HE, deJong B, Pellat FP, Fickel T, Kauffman J, and Prisley S. 2017. Lidar-based estimates of aboveground biomass in the continental US and Mexico using ground, airborne, and satellite observations. Remote Sensing of Environment 188:127-140. 10.1016/j.rse.2016.10.038

Potgieter AB, George-Jaeggli B, Chapman SC, Laws K, Suárez Cadavid LA, Wixted J, Watson J, Eldridge M, Jordan DR, and Hammer GL. 2017. Multi-Spectral Imaging from an Unmanned Aerial Vehicle Enables the Assessment of Seasonal Leaf Area Dynamics of Sorghum Breeding Lines. Frontiers in Plant Science 8:1532-1532. 10.3389/fpls.2017.01532

Rondeaux G, Steven M, and Baret F. 1996. Optimization of soil-adjusted vegetation indices. Remote Sensing of Environment 55:95-107. https://doi.org/10.1016/0034-4257(95)00186-7

S. Birth G, and R. McVey G. 1968. Measuring the Color of Growing Turf with a Reflectance Spectrophotometer1.

Samborski SM, Tremblay N, and Fallon E. 2009. Strategies to Make Use of Plant SensorsBased Diagnostic Information for Nitrogen Recommendations. Agronomy Journal 101:800816. 10.2134/agronj2008.0162Rx

Schaefer MT, and Lamb DW. 2016. A Combination of Plant NDVI and LiDAR Measurements Improve the Estimation of Pasture Biomass in Tall Fescue (Festuca arundinacea var. Fletcher). Remote Sensing 8. 10.3390/rs8020109

Silva CA, Hudak AT, Vierling LA, Klauberg C, Garcia M, Ferraz A, Keller M, Eitel J, and Saatchi S. 2017. Impacts of Airborne Lidar Pulse Density on Estimating Biomass Stocks and Changes in a Selectively Logged Tropical Forest. Remote Sensing 9. 10.3390/rs9101068

Smith RCG, Adams J, Stephens D, and Hick PT. 1995. Forecasting wheat yield in a Mediterranean-type environment from the NOAA satellite.

Stovall AEL, Vorster AG, Anderson RS, Evangelista PH, and Shugart HH. 2017. Nondestructive aboveground biomass estimation of coniferous trees using terrestrial LiDAR. Remote Sensing of Environment 200:31-42. 10.1016/j.rse.2017.08.013

Peer] reviewing PDF | (2019:04:36493:2:0:NEW 22 Jul 2019) 
724

725

726

727

728

729

730

731

732

733

734

735

736

737

738

739

740

741

742

743

744

745

746

747

748

749

750

751

752

753

754

755

756

757

758

759

760

761

762

763

764

765

766

767

768

769

770

771

772

773

774

Swatantran A, Dubayah R, Roberts D, Hofton M, and Blair JB. 2011. Mapping biomass and stress in the Sierra Nevada using lidar and hyperspectral data fusion. Remote Sensing of Environment 115:2917-2930. 10.1016/j.rse.2010.08.027

Tagarakis AC, Koundouras S, Fountas S, and Gemtos T. 2018. Evaluation of the use of LIDAR laser scanner to map pruning wood in vineyards and its potential for management zones delineation. Precision Agriculture 19:334-347. 10.1007/s11119-017-9519-4

Tilly N, Aasen H, and Bareth G. 2015. Fusion of Plant Height and Vegetation Indices for the Estimation of Barley Biomass. Remote Sensing 7:11449-11480. 10.3390/rs70911449

Tucker CJ, Elgin JH, McMurtrey JE, and Fan CJ. 1979. Monitoring corn and soybean crop development with hand-held radiometer spectral data. Remote Sensing of Environment 8:237-248. https://doi.org/10.1016/0034-4257(79)90004-X

Turner DP, Cohen WB, Kennedy RE, Fassnacht KS, and Briggs JM. 1999. Relationships between Leaf Area Index and Landsat TM Spectral Vegetation Indices across Three Temperate Zone Sites. Remote Sensing of Environment 70:52-68. https://doi.org/10.1016/S0034-4257(99)00057-7

Vahedi AA. 2016. Artificial neural network application in comparison with modeling allometric equations for predicting above-ground biomass in the Hyrcanian mixed-beech forests of Iran. Biomass \& Bioenergy 88:66-76. 10.1016/j.biombioe.2016.03.020

Vergara-Diaz O, Zaman-Allah MA, Masuka B, Hornero A, Zarco-Tejada P, Prasanna BM, Cairns JE, and Araus JL. 2016. A Novel Remote Sensing Approach for Prediction of Maize Yield Under Different Conditions of Nitrogen Fertilization. Frontiers in Plant Science 7. 10.3389/fpls.2016.00666

Wallace L, Lucieer A, Malenovsky Z, Turner D, and Vopenka P. 2016. Assessment of Forest Structure Using Two UAV Techniques: A Comparison of Airborne Laser Scanning and Structure from Motion (SfM) Point Clouds. Forests 7. 10.3390/f7030062

Wallace L, Lucieer A, and Watson C. 2014. Evaluating Tree Detection and Segmentation Routines on Very High Resolution UAV LiDAR Data.

Wang C, Nie S, Xi XH, Luo SZ, and Sun XF. 2017. Estimating the Biomass of Maize with Hyperspectral and LiDAR Data. Remote Sensing 9. 10.3390/rs9010011

Wang J, Ding J, Abulimiti A, and Cai L. 2018a. Quantitative estimation of soil salinity by means of different modeling methods and visible-near infrared (VIS-NIR) spectroscopy, Ebinur Lake Wetland, Northwest China. Peerj 6:e4703-e4703. 10.7717/peerj.4703

Wang X, Singh D, Marla S, Morris G, and Poland J. 2018b. Field-based high-throughput phenotyping of plant height in sorghum using different sensing technologies. Plant Methods 14. 10.1186/s13007-018-0324-5

Xie YC, Sha ZY, Yu M, Bai YF, and Zhang L. 2009. A comparison of two models with Landsat data for estimating above ground grassland biomass in Inner Mongolia, China. Ecological Modelling 220:1810-1818. 10.1016/j.ecolmodel.2009.04.025

Yang GJ, Liu JG, Zhao CJ, Li ZH, Huang YB, Yu HY, Xu B, Yang XD, Zhu DM, Zhang XY, Zhang RY, Feng HK, Zhao XQ, Li ZH, Li HL, and Yang H. 2017. Unmanned Aerial Vehicle Remote Sensing for Field-Based Crop Phenotyping: Current Status and Perspectives. Frontiers in Plant Science 8. 10.3389/fpls.2017.01111

Yang S, Yang X, and Mo J. 2018a. The application of unmanned aircraft systems to plant protection in China. Precision Agriculture 19:278-292. 10.1007/s11119-017-9516-7

Yang SX, Feng QS, Liang TG, Liu BK, Zhang WJ, and Xie HJ. 2018b. Modeling grassland above-ground biomass based on artificial neural network and remote sensing in the ThreeRiver Headwaters Region. Remote Sensing of Environment 204:448-455. 10.1016/j.rse.2017.10.011

Zarco-Tejada P, Miller J, Noland T, Mohammed G, and H. Sampson P. 2001. Scaling-up and model inversion methods with narrowband optical indices for chlorophyll content estimation in closed forest canopies with hyperspectral data.

Peer) reviewing PDF | (2019:04:36493:2:0:NEW 22 Jul 2019) 
775 Zhou X, Zheng HB, Xu XQ, He JY, Ge XK, Yao X, Cheng T, Zhu Y, Cao WX, and Tian YC.

776

777

778

779

780 2017. Predicting grain yield in rice using multi-temporal vegetation indices from UAV-based multispectral and digital imagery. Isprs Journal of Photogrammetry and Remote Sensing 130:246-255. https://doi.org/10.1016/j.isprsjprs.2017.05.003

Zolkos SG, Goetz SJ, and Dubayah R. 2013. A meta-analysis of terrestrial aboveground biomass estimation using lidar remote sensing. Remote Sensing of Environment 128:289-

781 298. 10.1016/j.rse.2012.10.017 
Figure 1

Study area and experimental design.

(A) Location of study area in Beijing. (B) The red line in the figure is the flight path of the UAV with LiDAR. (C) The red line in the figure is the flight path of the UAV with multispectral capabilities. (D) The study area and field plot. (E) Experimental design. (F)-(I) represents the four levels of plant density. $\mathrm{N}$ is the number of plants. Plot represents the field plot.
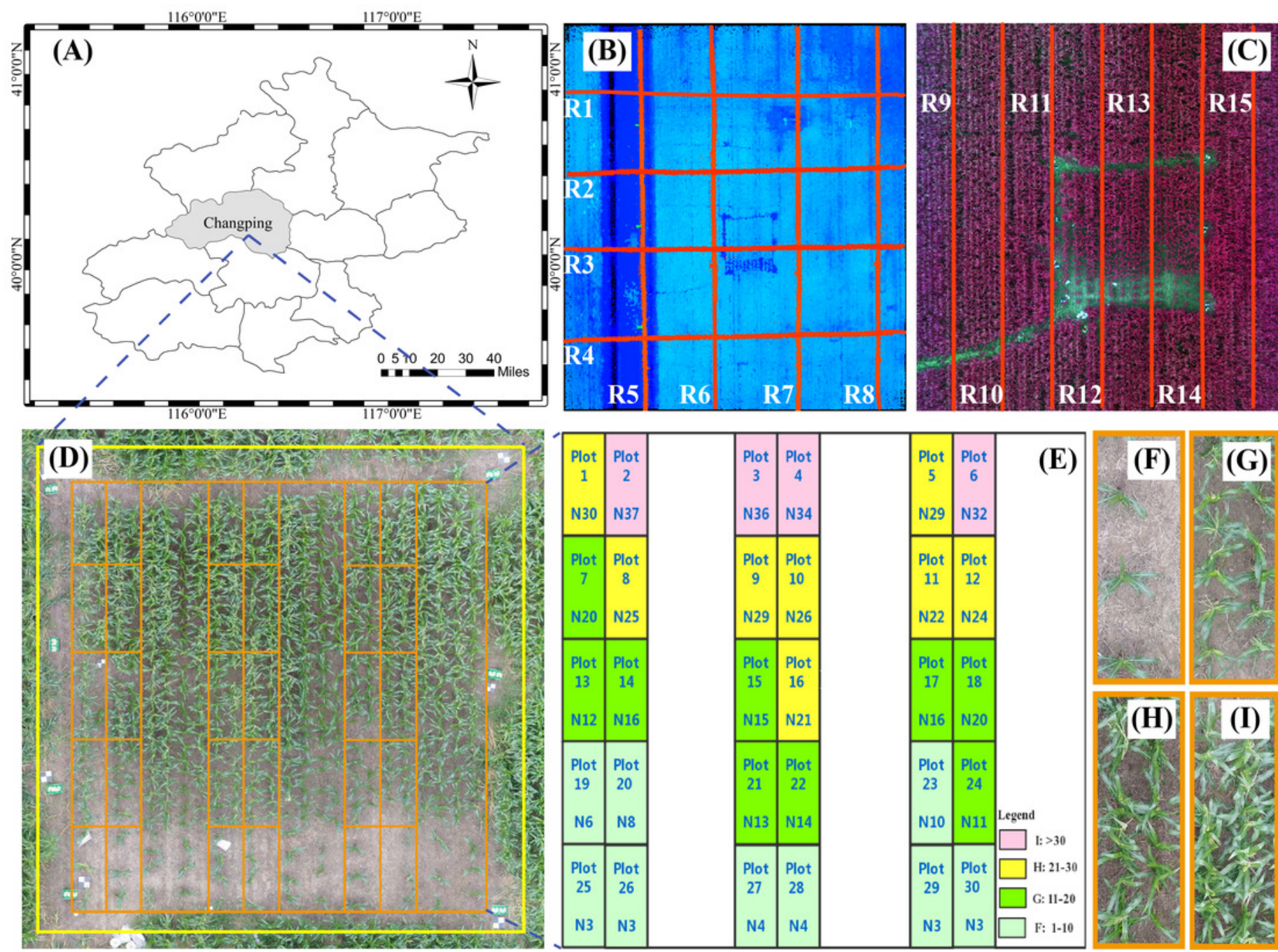

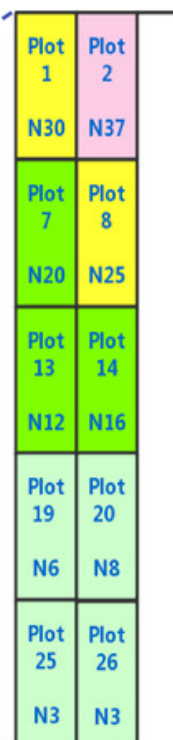

\begin{tabular}{|c|c|}
\hline $\begin{array}{c}\text { Plot } \\
3\end{array}$ & $\begin{array}{c}\text { Plot } \\
\text { N36 }\end{array}$ \\
N34 \\
\hline $\begin{array}{c}\text { Plot } \\
9\end{array}$ & $\begin{array}{c}\text { Plot } \\
10 \\
\text { N29 }\end{array}$ \\
N26 \\
\hline $\begin{array}{c}\text { Plot } \\
15\end{array}$ & $\begin{array}{c}\text { Plot } \\
16\end{array}$ \\
N15 & N21 \\
\hline Plot & Plot \\
21 & 22 \\
N13 & N14 \\
\hline Plot & Plot \\
27 & 28 \\
N4 & N4 \\
\hline
\end{tabular}
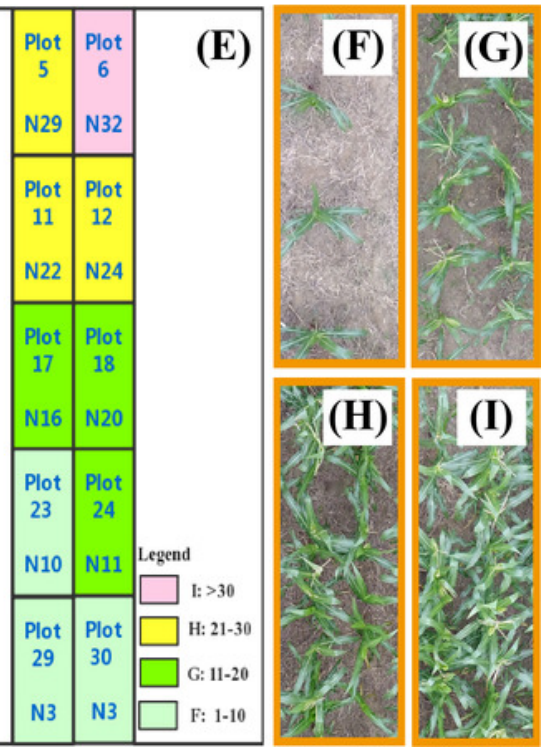
Figure 2

Reflectance spectra of soils with different AGB.

GRE, RED, REG, and NIR represents the green band, red band, red edge band, and nearinfrared band, respectively. F-I represents the density of plants.

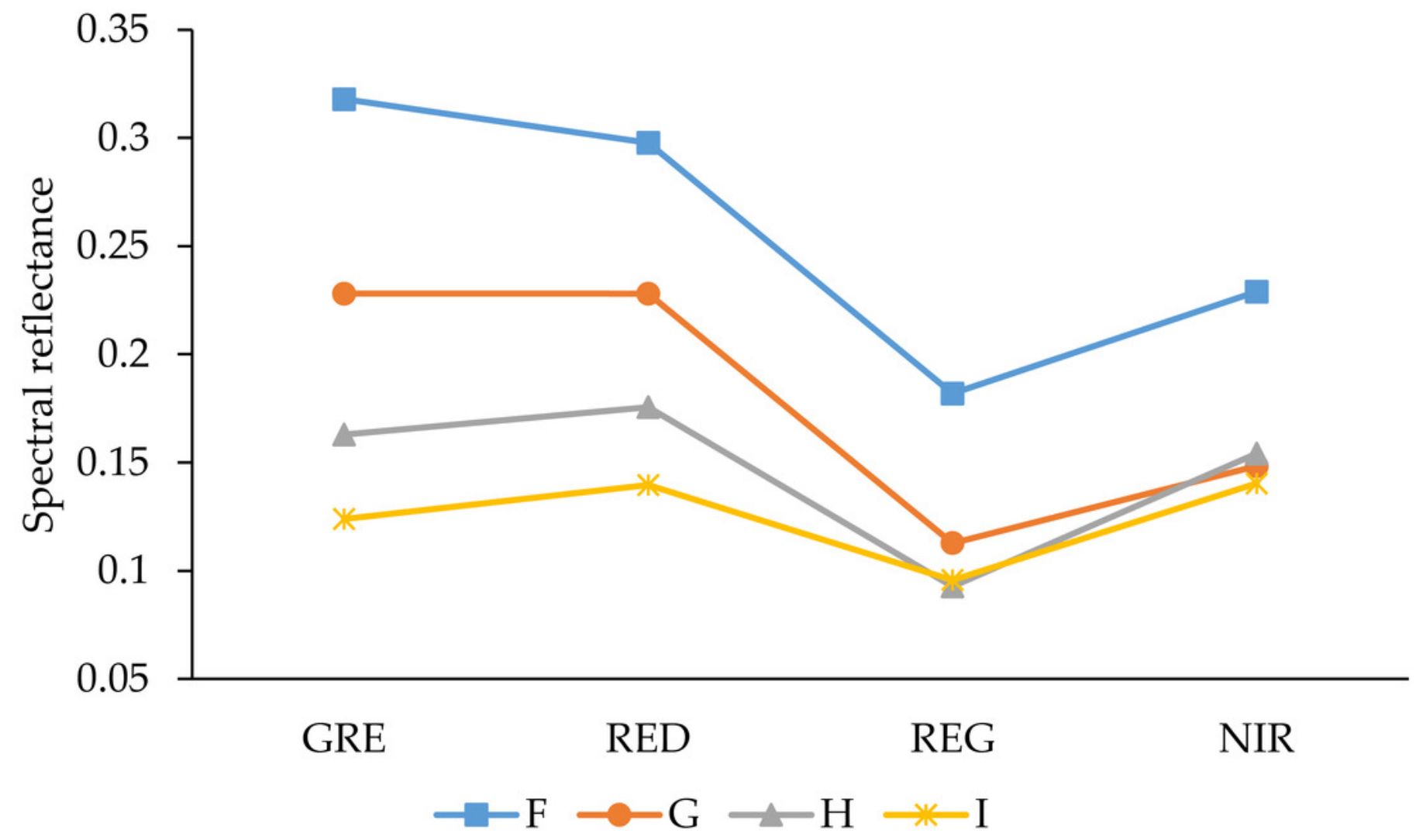


Figure 3

Research technology route.

(A) Field measurement data; (B) unmanned aerial vehicle LiDAR and multispectral image data preprocessing; (C) and estimation and verification of AGB.

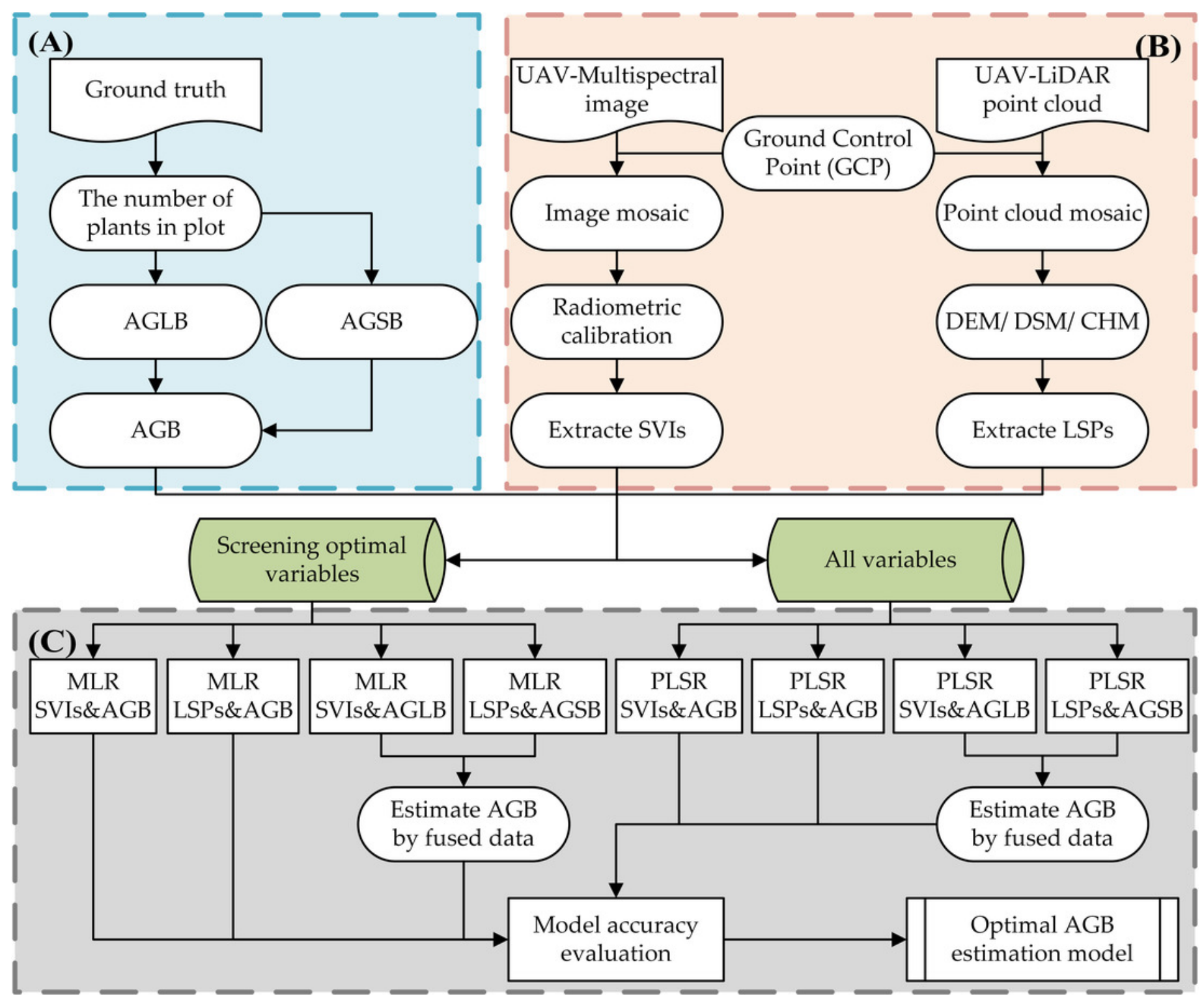


Figure 4

Schematic diagram of estimation of maize AGB based on stem-leaf separation strategy integrated with LiDAR and multispectral data.

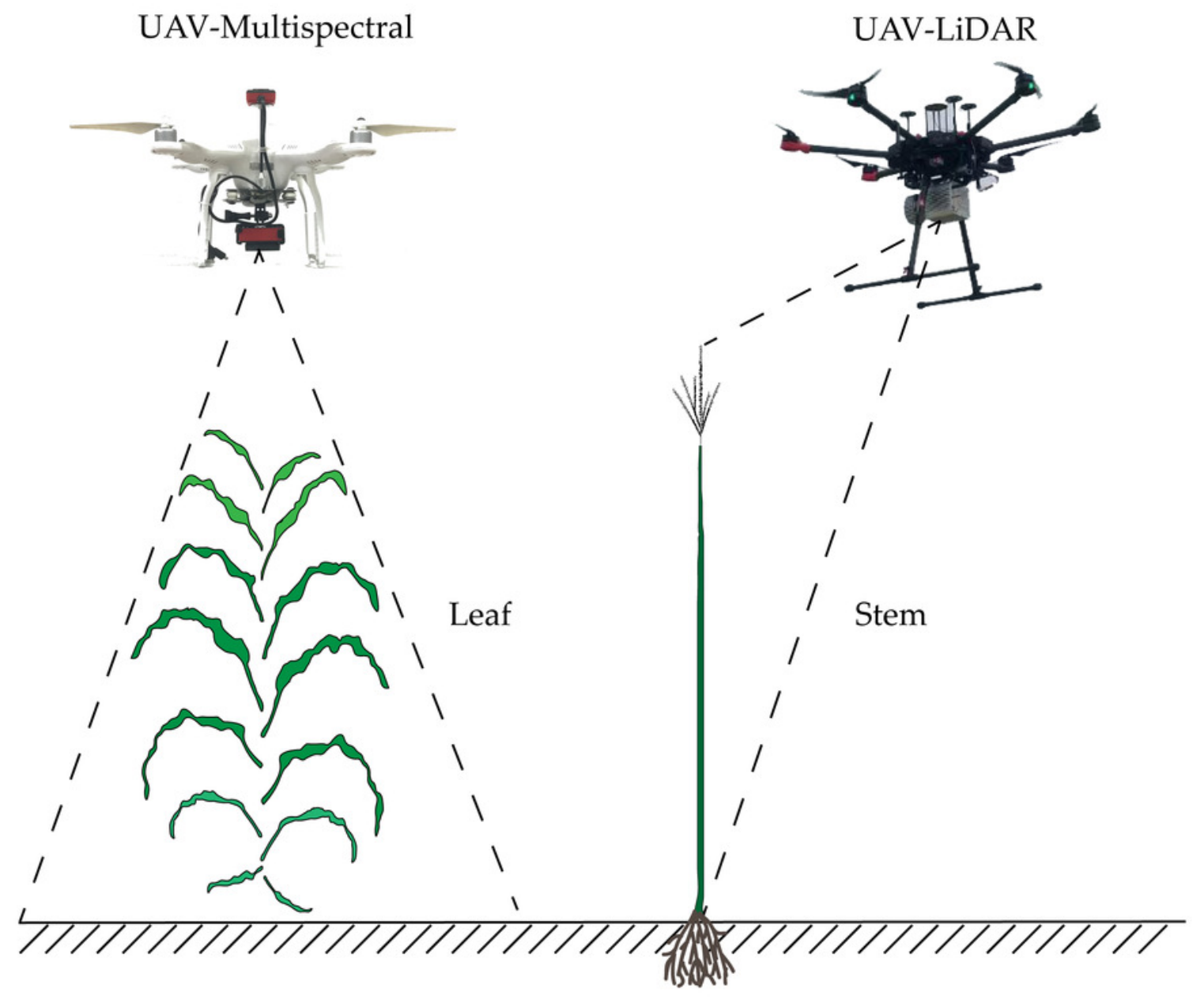




\section{Figure 5}

(A) Data exploration of SVIs and AGB and AGLB; (B) Data exploration of LSPs and AGB and AGSB.

The distribution of the variable itself is given in the diagonal area; the scatter plot and the curve fit between the two attributes are given at the lower left of the diagonal; the upperright digit of the diagonal indicates the relationship between the two attributes; the asterisk * indicates the degree of significance between attributes. 
(A) $\quad 0.50 \quad 0.70$ $1.6 \quad 1.9$ $0.20 \quad 0.35$ $0.20 \quad 0.35$

$\begin{array}{lll}0.5 & 1.5 & 2.5\end{array}$ $50 \quad 150$

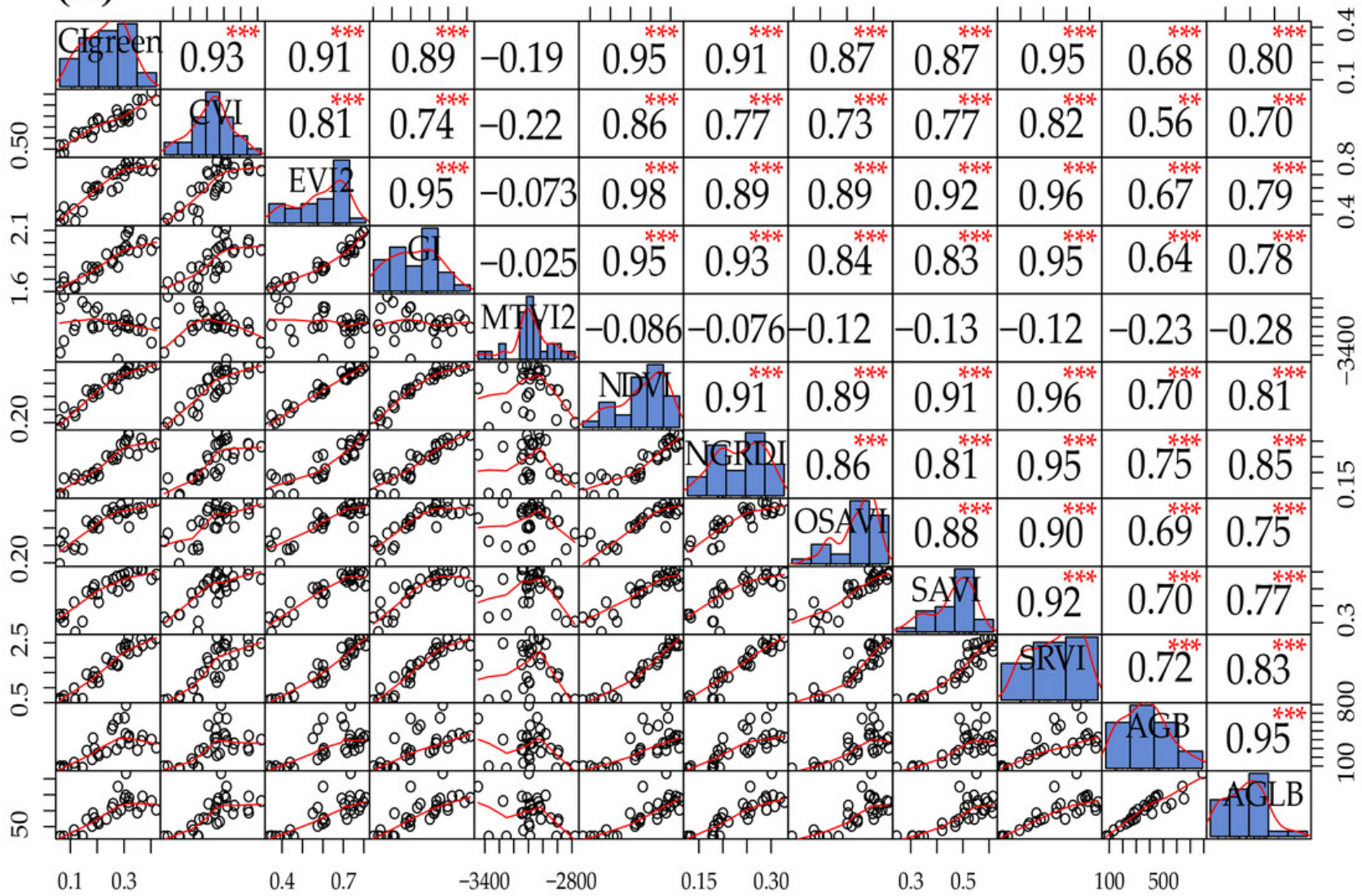
(B)
$1.9 \quad 2.1 \quad 2.3$
$\begin{array}{lll}2.1 & 2.3 & 2.5\end{array}$
$\begin{array}{lll}100 & 300 & 500\end{array}$

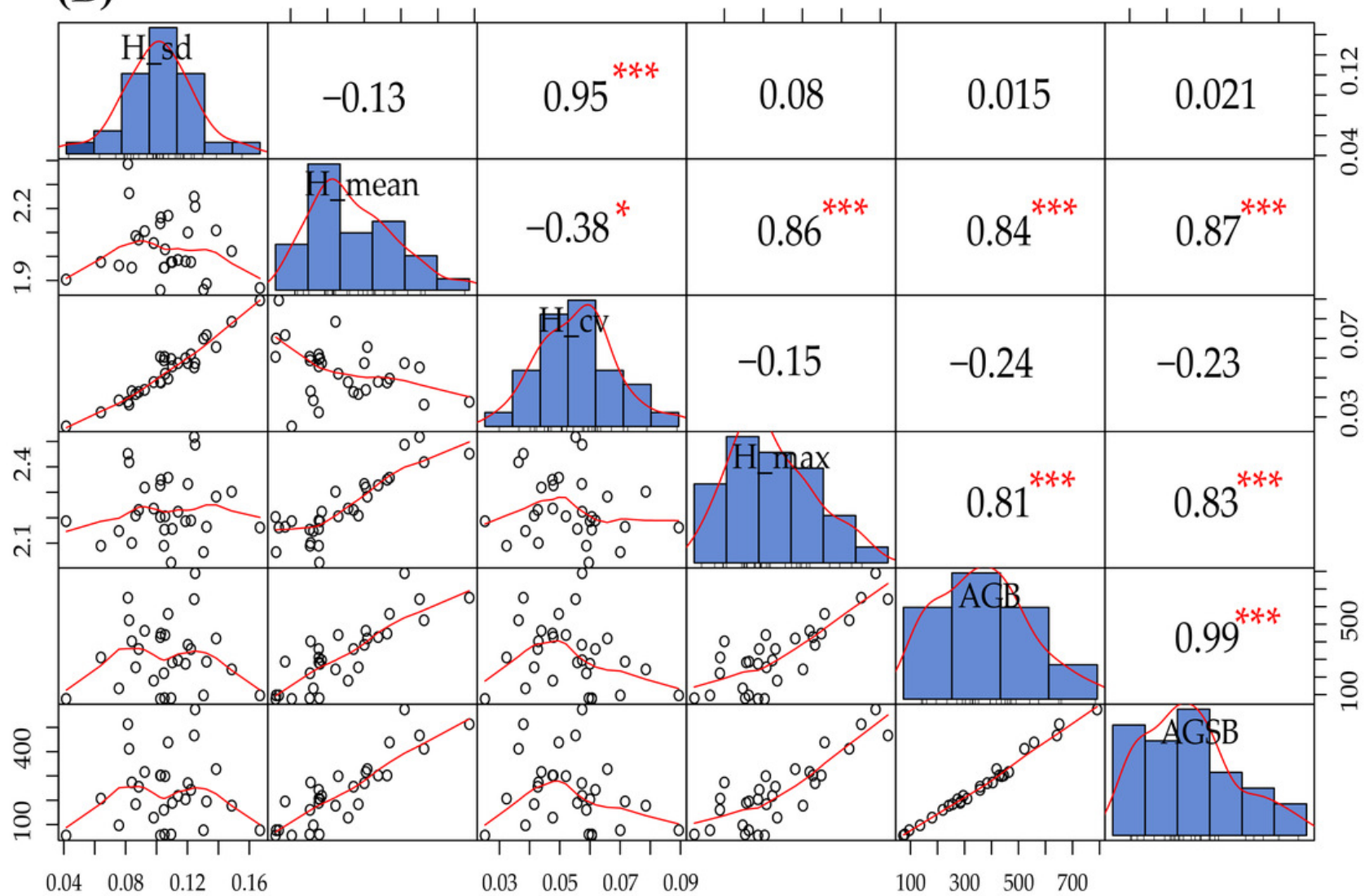

Peer] reviewing PDF | (2019:04:36493:2:0:NEW 22 Jul 2019) 
Figure 6

(A) Scatterplot of field-observed AGB versus AGB estimated by using two SVIs (MLR); (B) Scatterplot of field-observed AGB versus AGB estimated by using all SVIs (PLSR).

The red line represents the 1:1 line. 

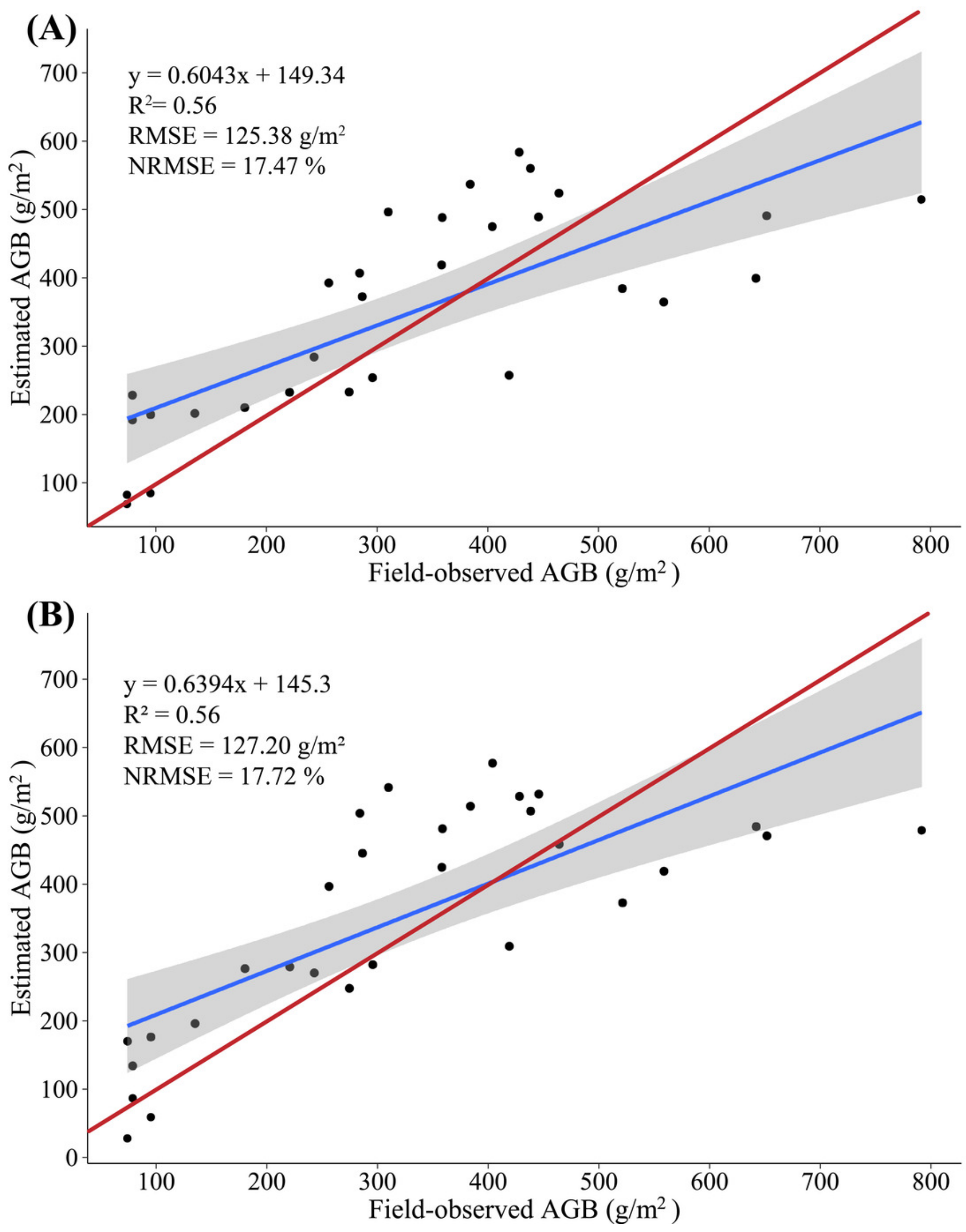
Figure 7

(A) Scatterplot of field-observed AGB versus AGB estimated by using two LSPs (MLR); (B) Scatterplot of field-observed AGB versus AGB estimated by using all LSPs (PLSR).

The red line represents the 1:1 line. 

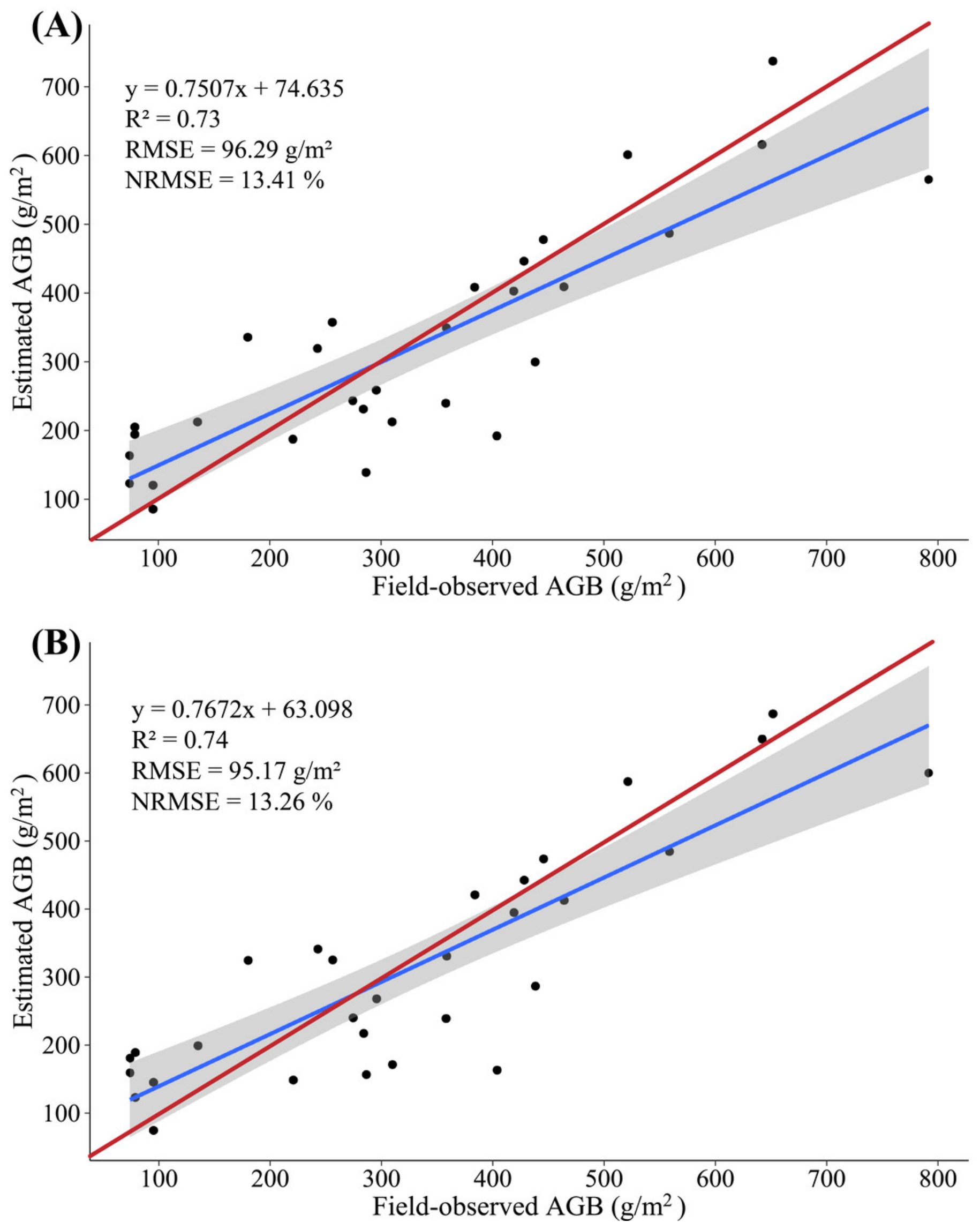
Figure 8

(A) Scatterplot of field-observed AGLB versus AGLB estimated by using two SVIs (MLR); (B) Scatterplot of field-observed AGSB versus AGSB estimated by using two LSPS (MLR).

The red line represents the 1:1 line. 

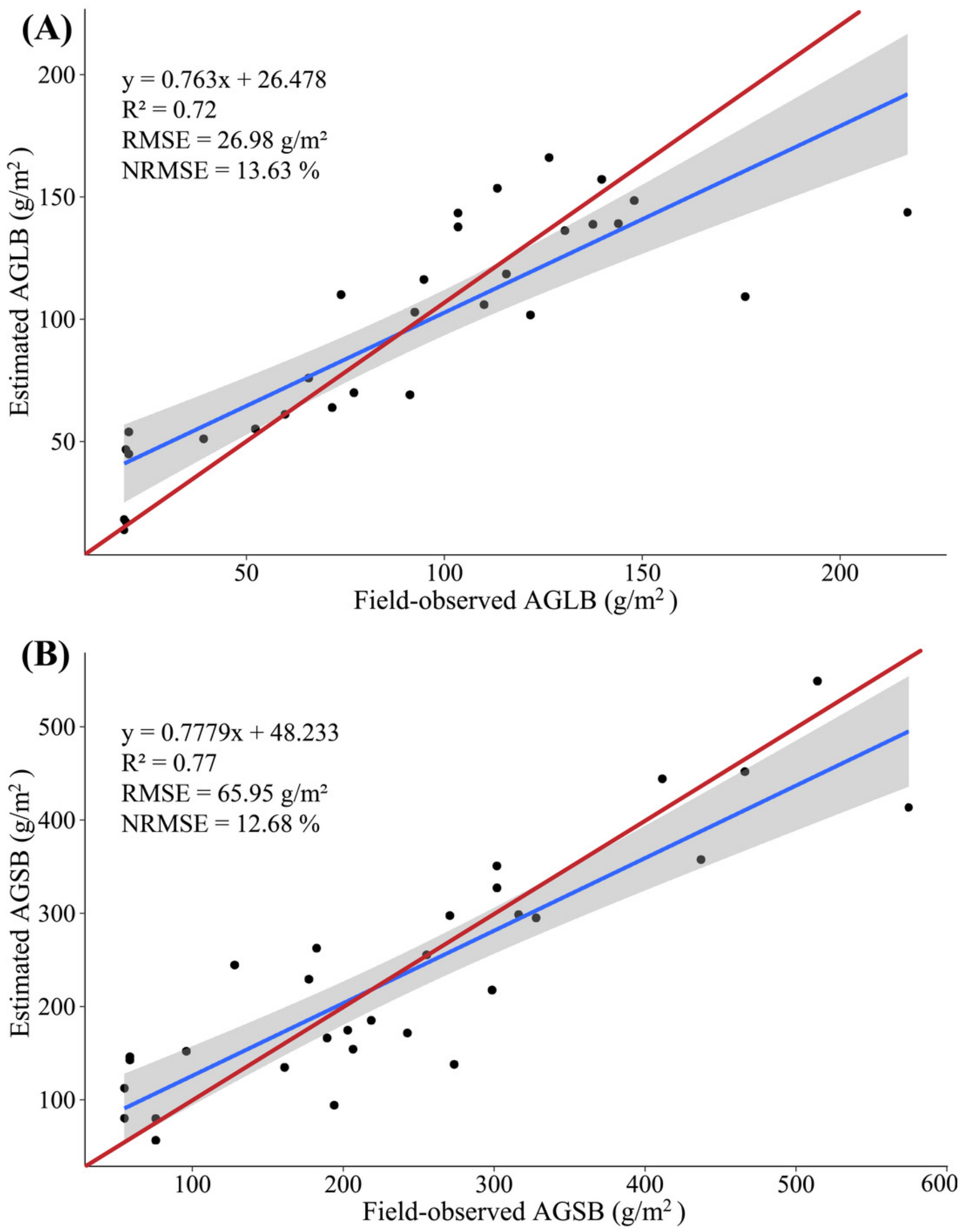
Figure 9

(A) Scatterplot of field-observed AGLB versus AGLB estimated by using all SVIs (PLSR); (B) Scatterplot of field-observed AGSB versus AGSB estimated by using all LSPS (PLSR).

The red line represents the 1:1 line. 

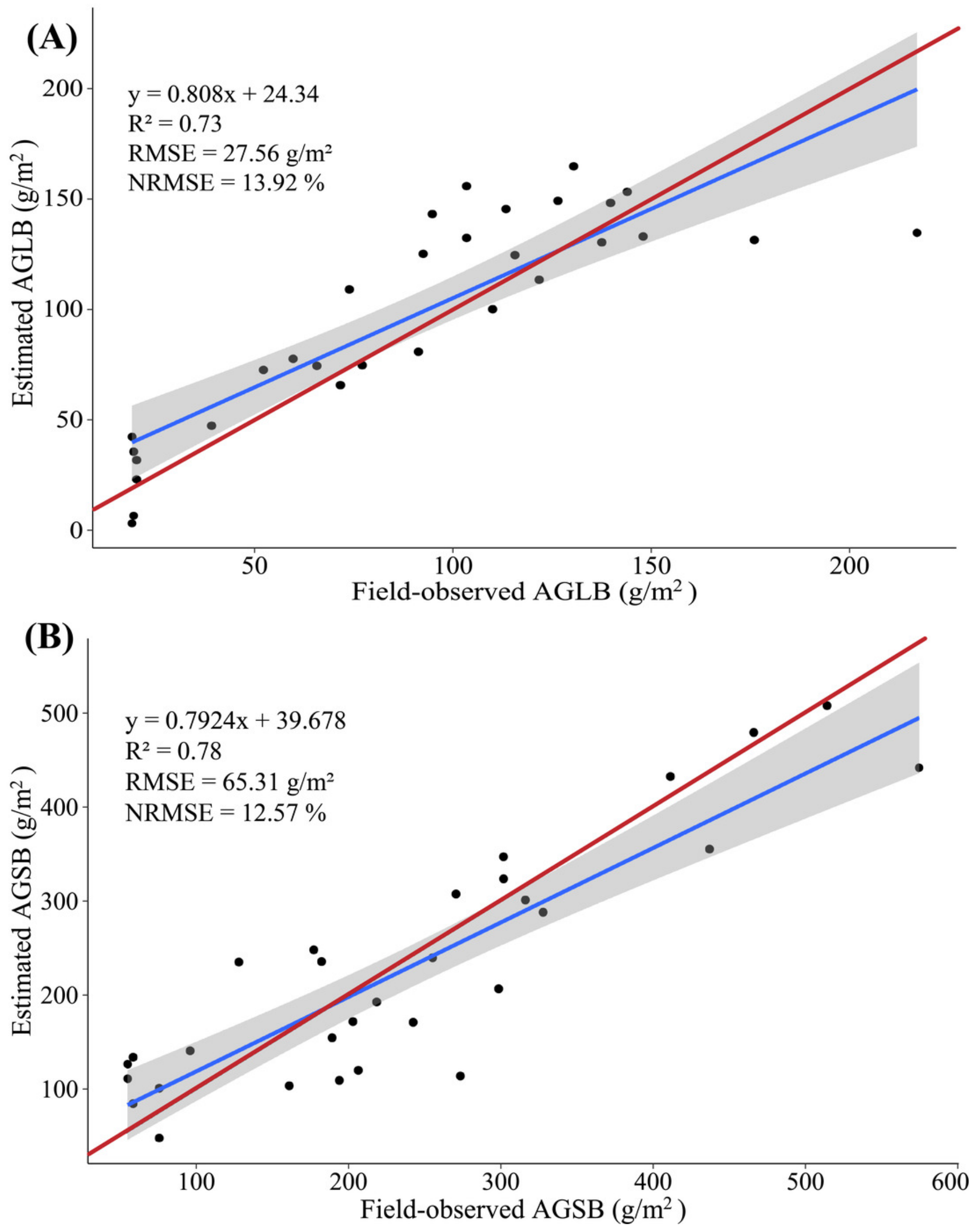


\section{Figure 10}

(A) Scatterplot of field-observed AGB versus $A G B$ estimated by merging multispectral and LiDAR data (MLR); (B) Scatterplot of field-observed AGB versus AGB estimated by merging multispectral and LiDAR data (PLSR).

The red line represents the 1:1 line. 

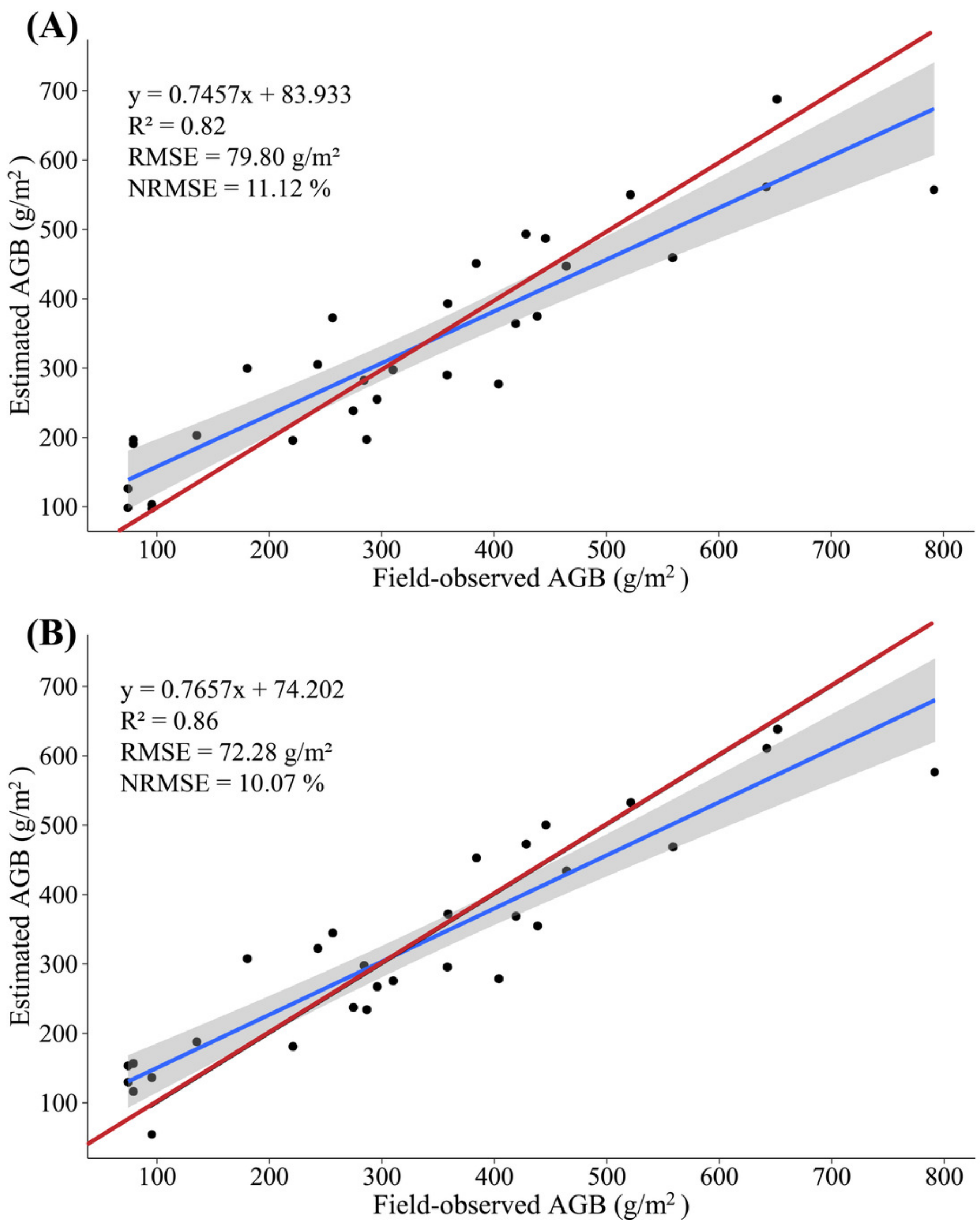
Figure 11

Comparison of accuracy of maize plant height extracted from digital and LiDAR data.

The blue dashed circle in the figure represents the height parameters of the extracted digital image contain some outliers in the lower planting density area. The outer number represents the field plot, and the inner number represents the plant height.

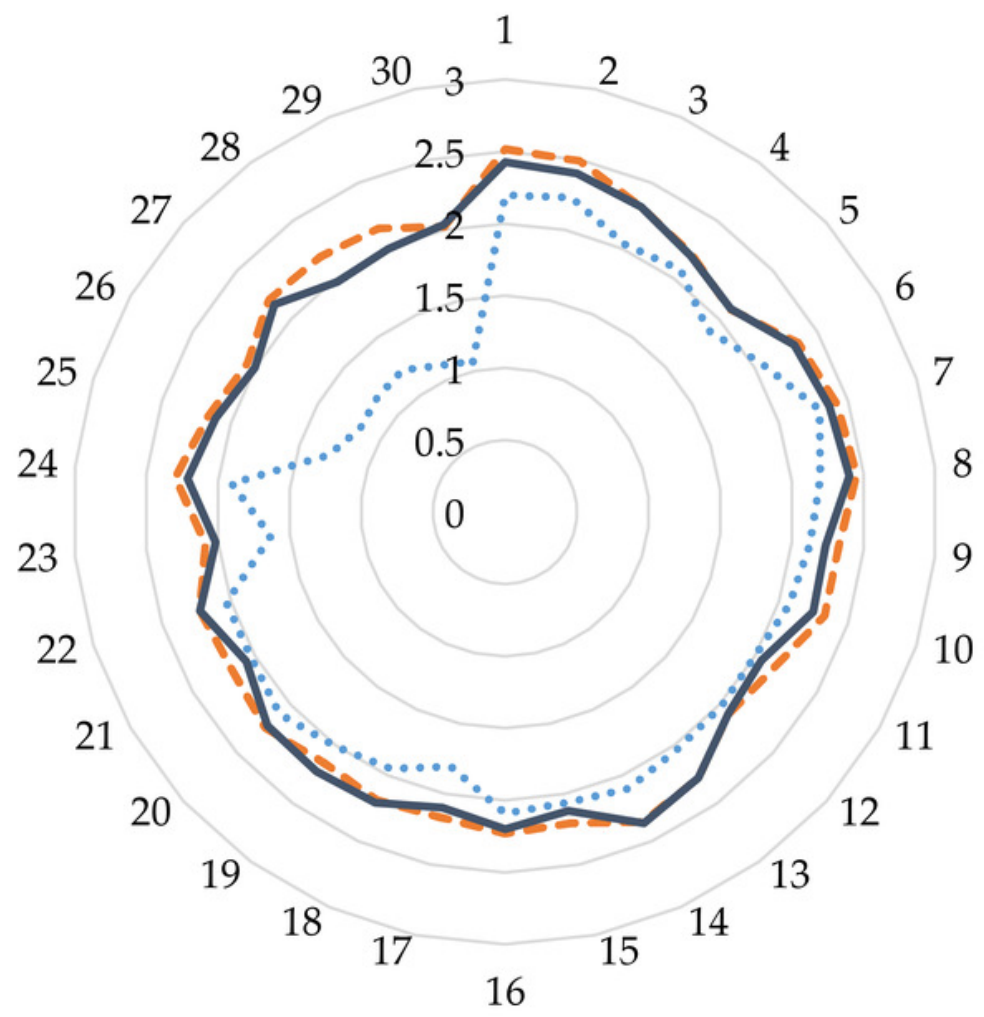

........ Digital image -----LiDAR point cloud

Ground truth 
Figure 12

Proportion of AGLB and AGSB in AGB.

$\square$ The proportion of AGLB in AGB $\square$ The proportion of AGSB in AGB

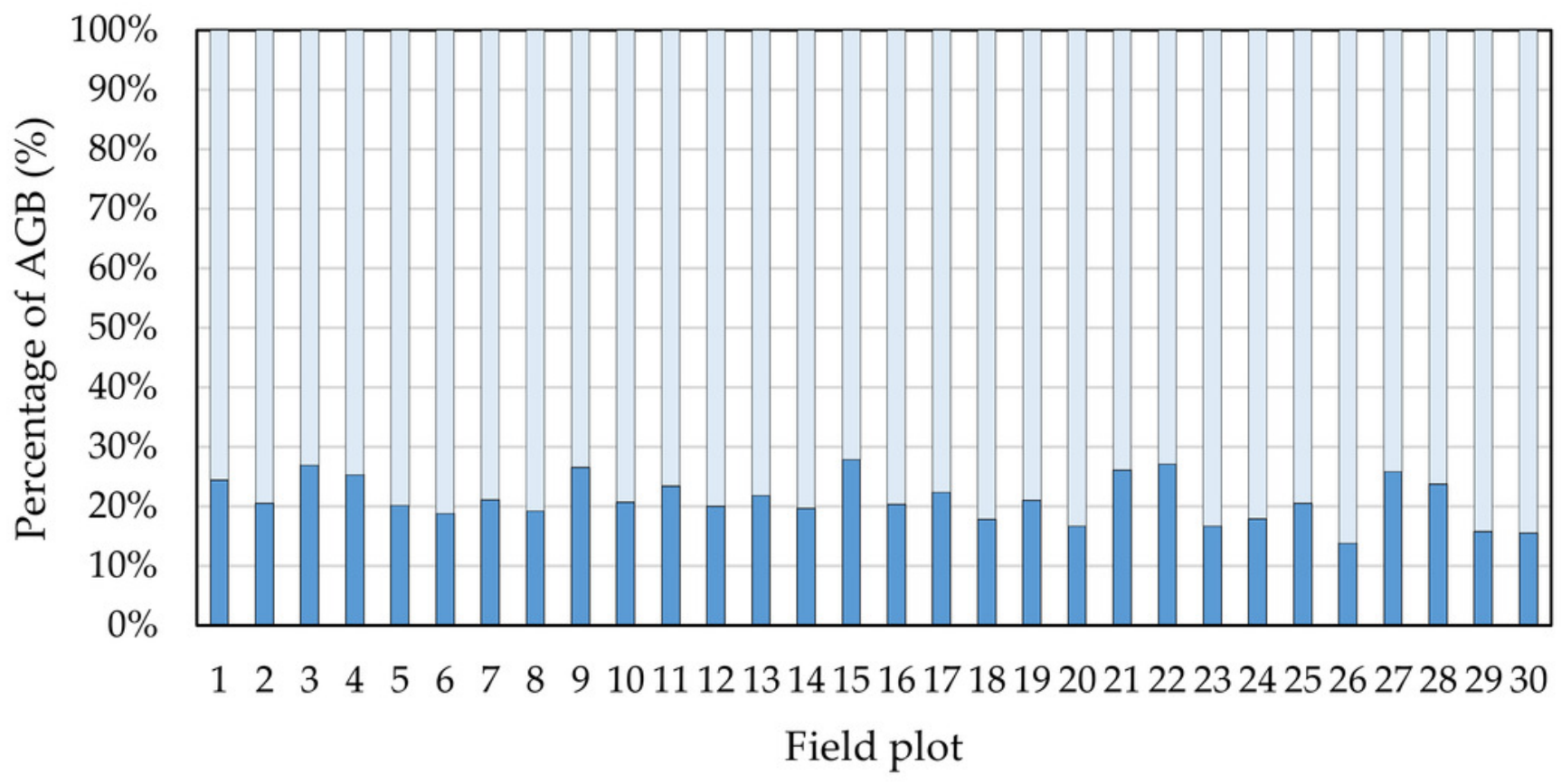


Table $\mathbf{1}$ (on next page)

LiDAR point cloud parameter of different routes. 


\begin{tabular}{|c|c|c|c|c|c|}
\hline Direction & Route & $\begin{array}{c}\text { Point cloud } \\
\text { density }\left(\mathrm{pts} / \mathrm{m}^{2}\right)\end{array}$ & $\begin{array}{l}\text { Spot diameter } \\
(\mathrm{cm})\end{array}$ & $\begin{array}{l}\text { Average ground } \\
\text { point spacing } \\
(\mathrm{cm})\end{array}$ & $\begin{array}{c}\mathrm{CHM} \\
\text { resolution } \\
(\mathrm{cm})\end{array}$ \\
\hline \multirow{4}{*}{ EW } & $\mathrm{R} 1$ & 112 & \multirow{8}{*}{0.75} & \multirow{8}{*}{2.39} & \multirow{8}{*}{1} \\
\hline & $\mathrm{R} 2$ & 280 & & & \\
\hline & R3 & 529 & & & \\
\hline & R4 & 213 & & & \\
\hline \multirow{4}{*}{ NS } & R5 & 228 & & & \\
\hline & R6 & 496 & & & \\
\hline & R7 & 417 & & & \\
\hline & $\mathrm{R} 8$ & 162 & & & \\
\hline
\end{tabular}

1 Note: EW indicates the east-west direction, NS indicates the north-south direction, and R1 to R8 are the various 2 routes of the UAV-LiDAR. 
Table 2 (on next page)

Optical vegetation indices used in this study and citations for biomass. 


\begin{tabular}{|c|c|c|}
\hline Metric & Equations & References \\
\hline CIgreen & $\rho_{\text {NIR }} / \rho_{\text {GREEN }}-1$ & (Gitelson et al. 2003) \\
\hline CVI & $\rho_{N I R} \times \rho_{R E D} / \rho_{G R E E N}^{2}$ & (Datt et al. 2003) \\
\hline EVI2 & $2.5\left(\rho_{N I R}-\rho_{R E D}\right) /\left(\rho_{N I R}+2.4 \rho_{R E D}+1\right)$ & (Jiang et al. 2008) \\
\hline GI & $\rho_{G R E E N} / \rho_{R E D}$ & (Smith et al. 1995) \\
\hline \multirow{2}{*}{ MTVI2 } & $1.5\left(1.2\left(\rho_{N I R}-\rho_{\text {GREEN }}\right)-2.5\left(\rho_{R E D}-\rho_{G R E E N}\right)\right)$ & \multirow{2}{*}{ (Haboudane et al. 2004) } \\
\hline & $\sqrt{\left(2 \rho_{N I R}+1\right)^{2}-\left(6 \rho_{N I R}-5 \sqrt{\left.\rho_{R E D}\right)-0.5}\right.}$ & \\
\hline NDVI & $\left(\rho_{N I R}-\rho_{R E D}\right) /\left(\rho_{N I R}+\rho_{R E D}\right)$ & (Tucker et al. 1979) \\
\hline NGRDI & $\left(\rho_{\text {GREEN }}-\rho_{R E D}\right) /\left(\rho_{\text {GREEN }}+\rho_{R E D}\right)$ & (Zarco-Tejada et al. 2001) \\
\hline OSAVI & $(1+Y)\left(\rho_{N I R}-\rho_{R E D}\right) /\left(\rho_{N I R}+\rho_{R E D}+Y\right)(Y=0.16)$ & (Rondeaux et al. 1996) \\
\hline SAVI & $(1+L)\left(\rho_{N I R}-\rho_{R E D}\right) /\left(\rho_{N I R}+\rho_{R E D}+L\right)(L=0.5)$ & (Huete 1988) \\
\hline SRVI & $\rho_{N I R} / \rho_{R E D}$ & (S. Birth \& R. McVey 1968) \\
\hline
\end{tabular}


Table 3 (on next page)

LiDAR-derived metrics for estimating biomass parameters. 


\begin{tabular}{ccc}
\hline Metric & Equations & Description \\
\hline H_max & H_max $=\max \left(\mathrm{H}_{i}\right), 1 \leq i \leq N$ & Maximum height of plants \\
H_mean & H_mean $=\frac{1}{N} \sum_{i=1}^{N} \mathrm{H}_{i}$ & Mean height of plants \\
H_sd & H_sd $=\sqrt{\frac{1}{N-1} \sum_{i=1}^{N}\left(\mathrm{H}_{i}-\mathrm{H}_{-} \text {mean }\right)^{2}}$ & Standard deviation of plants height \\
H_cv & H_cv $=$ H_sd/H_mean & Variation coefficient of plants height \\
\hline & Note: In the table, $\mathrm{H}_{i}$ is the height of maize plants.
\end{tabular}




\section{Table 4 (on next page)}

Basic statistics of the plant height measurements. 


\begin{tabular}{cccccc}
\hline Data & Mean (m) & Maximum $(\mathrm{m})$ & Minimum $(\mathrm{m})$ & $\mathrm{SD}\left(\mathrm{m}^{2}\right)$ & $\mathrm{CV}(\%)$ \\
\hline Digital & 1.86 & 2.29 & 1.06 & 0.39 & 0.21 \\
LiDAR & 2.23 & 2.51 & 2.02 & 0.13 & 0.06 \\
Ground-truth & 2.18 & 2.42 & 1.97 & 0.13 & 0.06 \\
\hline
\end{tabular}

1 


\section{Table 5 (on next page)}

Modeling statistics between the estimated and the measured AGB. 


\begin{tabular}{ccccc}
\hline \multirow{2}{*}{ Models } & \multirow{2}{*}{$\begin{array}{c}\text { Different } \\
\text { combinations }\end{array}$} & $\mathbf{R}^{\mathbf{2}}$ & RMSE (g/m $\mathbf{m}^{\mathbf{2}}$ & NRMSE (\%) \\
\cline { 3 - 5 } & AGB-SVI & 0.56 & 125.38 & 17.47 \\
\multirow{3}{*}{ MLR } & AGB-LSP & 0.73 & 96.29 & 13.41 \\
& AGB-SVI+LSP & 0.82 & 79.80 & 11.12 \\
\hline \multirow{2}{*}{ PLSR } & AGB-SVI & 0.56 & 127.20 & 17.72 \\
& AGB-LSP & 0.74 & 95.17 & 13.26 \\
& AGB-SVI+LSP & 0.86 & 72.28 & 10.07 \\
\hline
\end{tabular}

1 Note: In the table, AGB-SVI, AGB-LSP, and AGB-SVI+LSP represent three different combinations for MLR method.

2 AGB-SVI + LSP represents the estimation of AGB based on stem-leaf separation strategy with LiDAR and multispectral data. 
Table 6(on next page)

Multiple comparison result for one-way ANOVA. 


\begin{tabular}{|c|c|c|c|c|c|c|}
\hline \multirow{2}{*}{$\begin{array}{l}\text { Density } \\
\text { (I) }\end{array}$} & \multirow{2}{*}{$\begin{array}{c}\text { Density } \\
\text { (J) }\end{array}$} & \multirow{2}{*}{$\begin{array}{c}\text { Mean } \\
\text { difference } \\
(\mathrm{I}-\mathrm{J})\end{array}$} & \multirow{2}{*}{$\begin{array}{l}\text { Standard } \\
\text { error }\end{array}$} & \multirow{2}{*}{ P-value } & \multicolumn{2}{|c|}{ 95\% Confidence interval } \\
\hline & & & & & Lower limit & Upper limit \\
\hline \multirow{3}{*}{$\mathrm{F}$} & G & -242.22 & 55.37 & 0.000 & -356.05 & -128.40 \\
\hline & $\mathrm{H}$ & -318.02 & 57.07 & 0.000 & -435.34 & -200.69 \\
\hline & I & -420.17 & 70.58 & 0.000 & -565.26 & -275.07 \\
\hline \multirow{3}{*}{ G } & $\mathrm{F}$ & 242.22 & 55.37 & 0.000 & 128.40 & 356.05 \\
\hline & $\mathrm{H}$ & -75.79 & 57.07 & 0.196 & -193.11 & 41.53 \\
\hline & $\mathrm{I}$ & -177.94 & 70.58 & 0.018 & -323.03 & -32.84 \\
\hline \multirow{3}{*}{$\mathrm{H}$} & $\mathrm{F}$ & 318.02 & 57.07 & 0.000 & 200.69 & 435.34 \\
\hline & G & 75.79 & 57.07 & 0.196 & -41.53 & 193.11 \\
\hline & $\mathrm{I}$ & -102.15 & 71.93 & 0.167 & -250.00 & 45.70 \\
\hline \multirow{3}{*}{$\mathrm{I}$} & $\mathrm{F}$ & 420.17 & 70.58 & 0.000 & 275.07 & 565.26 \\
\hline & G & 177.94 & 70.58 & 0.018 & 32.84 & 323.03 \\
\hline & $\mathrm{H}$ & 102.15 & 71.93 & 0.167 & -45.70 & 250.00 \\
\hline
\end{tabular}

